\title{
Utilización de cenizas volantes en la fabricación de cementos
}

\author{
LUIS ULLOA FERNANDEZ DE S.AMAMIIID: \\ Licenciado en diencias cumica:
}

\section{INTRODUCCION}

La crisis de la energía, que tomó gran importancia a partir de 1973, ha originado la aceleración de estudios y posibilitado el desarrollo de otras fuentes alternativas del petróleo. El aprovechamiento de la energía latente que tienen algunos materiales volcánicos, o subproductos de procesos industriales (escorias siderúrgicas, cenizas volantes), ha merecido gran atención en la fabricación de cemento.

Las normas para la recepción y utilización de cementos han tomado en consideración el aprovechamiento de estos materiales, definiendo los cementos portland con adiciones hidráulicamente activas (designación PA), que pueden contener hasta un $20 \%$ de adiciones.

La utilización de estos subproductos ha pasado a ser un deber nacional y un imperativo económico, y han encontrado en la industria de la construcción y trabajos púbjicos un buen empleo, al aportar algunas mejoras a los materiales a los que son incorporados.

Las centrales térmicas que queman carbón pulverizado recuperan polvos finos llamados cenizas volantes. Esta recuperación es necesaria a fin de evitar la polución atmosférica.

La evacuación de las cenizas volantes resulta difícil y molesta, ya que hay que disponer de grandes escombreras en las proximidades de las Centrales.

ENDESA, en el año 1973, informó acerca de la previsión de producción de cenizas en sus Centrales Térmicas, tal como indicamos en la tabla:

Producción actual y prevista de cenizas (en miles t/año)

\begin{tabular}{lrrrrr}
\hline & 1974 & 1976 & 1977 & 1978 & 1979 \\
\hline Puentes & 150 & 900 & 1.800 & 2.700 & 3.600 \\
Compostilla & 420 & 420 & 600 & 600 & 900 \\
Escatrón & 120 & 120 & 120 & 360 & 720 \\
\hline TOTAL (miles/t) & 690 & 1.440 & 2.520 & 3.660 & 5220 \\
\hline
\end{tabular}

\footnotetext{
* Memoria presentada por el autor para optar al Grado de Licenciado en Ciencias por la Facultad de Quimica de ia Universidad de Santiago de Compostela.

Trabajo realizado en los laboratorios de CEMENTOS NOROESTE, S. A., de Oural (Lugo) bajo la dirección del Catedrático Director del Departamento de Quimica Técnica de dicha Facultad, y con la orientación y ayuda del Lcdo. en Ciencias Químicas don Arturo iMARTINEZ MARTINEZ, Director Técnico de la mencionada Empresa.
} 
En la figura 1 se indica el emplazamiento de las Centrales Térmicas y el de nuestras factorías de Oural y Toral de los Vados.

En el pasado año hemos empleado en nuestras Factorías 150.000 t de cenizas volantes. En los próximos años podremos emplear en la fabricación de cementos aproximadamente $250.000 \mathrm{t}$ /año de cenizas volantes.

El abastecimiento está por tanto garantizado y es muy interesante seguir investigando para tratar de poder utilizar mayores volúmenes de estos subproductos que se obtienen en las Centrales Térmicas.

\section{E. N. D. E. S. A.}

\section{COMUNICACIONES PRINCIPALES DE LAS CENTRALES TERMOELECTRICAS}

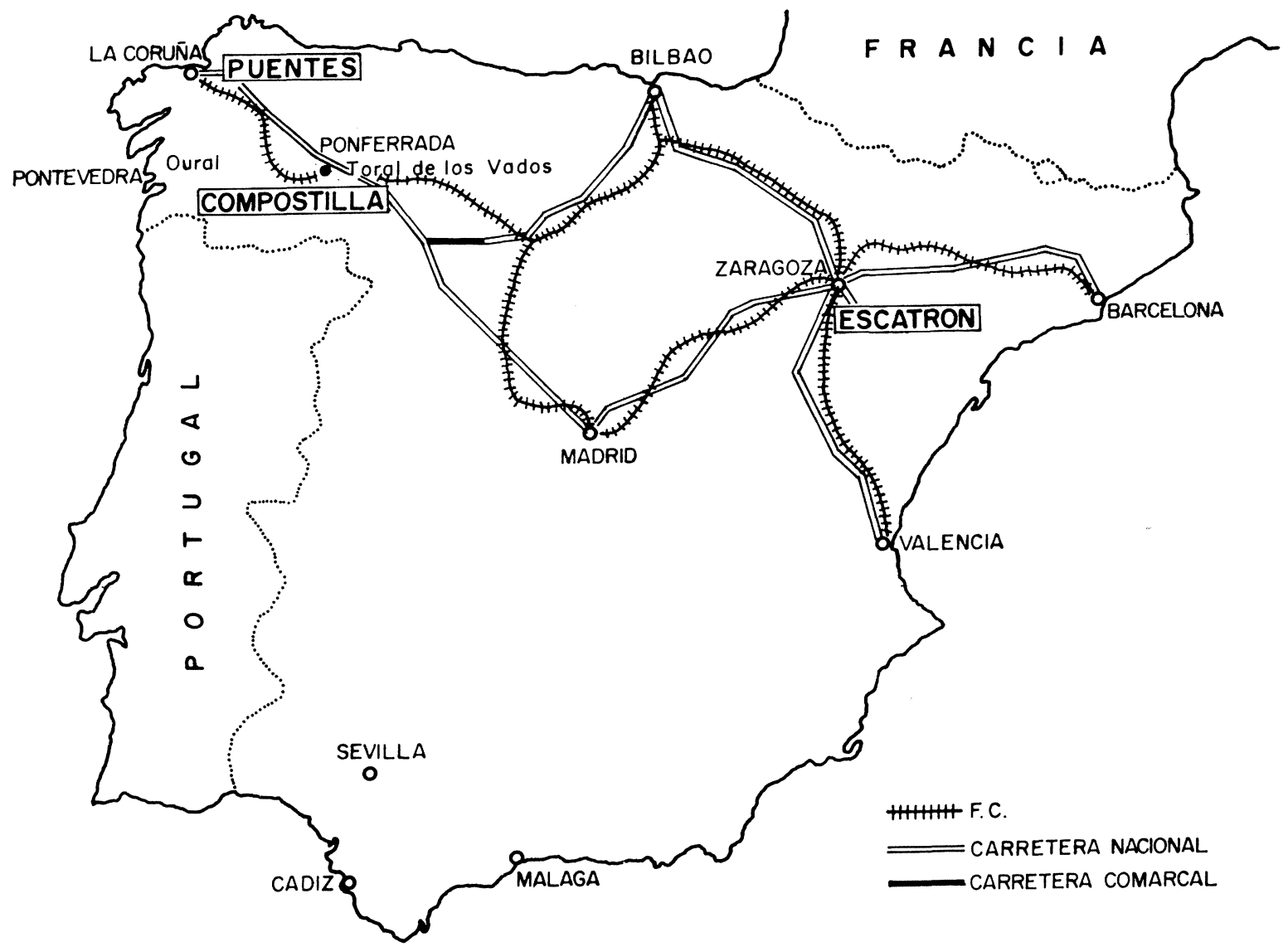

Fig. 1

24 


\section{OBJETO}

Dada la ubicación de la Factoría - las distancias a posibles yacimientos o fuentes de suministro de estos materiales-, hemos estudiado la fabricación de cementos tipo PA y PUZ mediante la adición al clínker de cenizas volantes, subproducto de la combustión de carbón en las Centrales Térmicas.

El presente trabajo es uno de los realizados en los Laboratorios de Cementos del Noroeste con el fin de tratar de conocer la utilidad y aprovechamiento de estos materiales.

En el año 1965 Cementos Noroeste inició estudios a escala de Laboratorio para determinar la posibilidad de utilizar, en su proceso de fabricación, las cenizas volantes que se producen en las Centrales Térmicas más próximas a su Factoría de Oural, con el deseo de obtener cementos i.dóneos para, ser empleados en obras hidráulicas, en las que se requieren aglomerantes de bajo calor de hidratación y de gran estabilidad a los efectos de lavado de las aguas puras.

Dada la importancia de las obras marítimas en Galicia, se ampliaron estos estudios con el deseo de conocer el efecto benefactor de las cenizas en los hormigones que habrán de estar sometidos a la acción de las aguas de mar.

Como consecuencia de los buenos resultados obtenidos se realizaron experiencias a escala industrial, que han permitido utilizar hasta la fecha algo más de 1 millón de $t$ de cenizas volantes en la fabricación de cementos.

Este trabajo es un intento de conocer alguna de las propiedades de los cementos fabricados a escala industrial, con contenidos en cenizas de $13 \%$ y $23 \%$ aproximadamente, y que según la Norma actualmente en vigor RC-75, publicada en el Boletín Oficial del Estado núms. 206 y 207, de fechas 28 y 29 de agosto de 1975, reciben la designación PA-350 y PUZ-II-350.

A fin de disponer de un término comparativo en la misma instalación industrial, con el mismo clínker, sin adición de cenizas y moliéndolo a la finura que se especifica en el trabajo, hemos obtenido cementos portland puros, que según la Norma RC-75, reciben la designación P-450-ARI.

\section{ANTECEDENTES BIBLIOGRAFICOS}

Los materiales puzolánicos han sido utilizados en la construcción por los etruscos, los griegos y los romanos; y, sin duda, también otros pueblos de la antigüedad los utilizaron con éxito mezclándolos con cal. Los romanos hicieron un gran número de obras portuarias y fluviales, que han resistido durante más de 20 siglos (trabajos portuarios de Ostia, Puerto de Nerón en Accio, Coliseo Romano, etc.), mezclando cal y puzolana, la cual tiene la ventaja sobre la cal de poder endurecer bajo el agua (material hidráulico).

Estos materiales puzolánicos que utilizaban eran productos naturales (cenizas volcánicas).

Hoy se sabe que las cenizas volantes son análogas a las puzolanas naturales de origen volcánico.

Desde estos períodos antiguos hasta los trabajos de Vicat sobre las cales hidráulicas, comenzados en 1812, los morteros puzolánicos han sido los únicos utilizados de una manera regular en los trabajos hidráulicos.

El interés de las cenizas volantes puede remontarse al año 1895, fecha en que las fábricas de cemento empiezan a utilizar como combustible carbón pulverizado. En 1910 se empieza a utilizar también en calderas de vapor y comienza, a partir de esa fecha, un rápido creci- 
miento en la utilización de carbón pulverizado en Centrales Térmicas, al tiempo que un severo incremento de las restricciones reguladoras de las descargas de humos, sobre todo en áreas densamente pobladas, motivo por el cual el problema de la recuperación de cenizas volantes se desarrolló a gran escala.

Al incrementarse la producción de estos materiales, y solucionarse el de su recuperación, surgió rápidamente el problema, aún actual, de su eliminación. Debido a ello se comenzaron a estudiar sus posibles usos.

Estos estudios comenzaron en EE.UU., pero no sólo en este país, sino también en muchos otros industrializados que utilizaban carbón a gran escala, como Alemania, Francia, Inglaterra, Polonia, etc.

Los precursores en la utilización fueron también los EE.UU. que en 1930 desarrollaron su aplicación a la fabricación de productos de hormigón, y como adición al hormigón mismo en la construcción de obras hidráulicas (Presa de Hungry Horse). De 12 millones de $t$ de cenizas volantes producidas en 1959, se pasará a 40 millones de $t$ en 1980, por lo que se ve la necesidad de abrir nuevos campos de utilización.

Hoy en día, en muchos países, las cenizas volantes llevan camino de no ser una carga, sino por el contrario una fuente de ingresos muy interesante.

En Francia se puede considerar que la utilización industrial de las cenizas volantes comenzó hacia 1951. Actualmente se emplean algo más de 1 millón de t/año; solamente en la fabricación de cementos, y con relación a su producción, es uno de los países que más cenizas volantes consume en usos industriales.

\section{PARTE TEORICA}

4.1. Este trabajo consiste en el estudio comparativo de las propiedades de cementos obtenidos a escala industrial, moliendo conjuntamente clínker de cemento portland, piedra de yeso crudo y cenizas volantes. Como término comparativo se fabricó un cemento portland puro (compuesto solamente de clínker y piedra de yeso crudo).

Se analizan las características físicas, químicas y mecánicas de los cementos así obtenidos. y se determinan las posibles mejoras que aportan las cenizas volantes.

\subsection{Materiales utilizados}

\subsubsection{Clínker de cemento portland}

Fabricado en la factoría de Oural (en 2 líneas en paralelo análogas, compuestas por hornos rotativos Humboldt de vía seca, provistos de un intercambiador de calor en suspensión de gas con 4 etapas de ciclones, y un enfriador Fuller de parrilla horizontal).

En la parte experimental del trabajo se dan las principales características de los clínkeres obtenidos.

\subsubsection{Piedra de yeso crudo}

Procedente de Burgos es transportado a nuestra factoría por los medios normales de ferrocarril o camión, alimentándose con él las tolvas de los molinos de cemento. 


\subsubsection{Cenizas volantes}

Es el material importante a estudiar en este trabajo. Son los residuos sólidos procedentes de la combustión de carbón pulverizado en las Centrales Térmicas.

En el hogar la temperatura es tan elevada que las cenizas funden, al menos parcialmente. Las partículas que no se aglomeran son arrastradas en suspensión de gas a lo largo del circuito de intercambio térmico que a éstas se le obliga a recorrer.

El enfriamiento de las cenizas es rápido. Como consecuencia los silicatos fundidos en el hogar no disponen del tiempo necesario para la cristalización, quedando en estado vítreo. Este es el fundamento de la actividad hidráulica de las cenizas volantes, al igual que el de las cenizas de los volcanes (puzolanas naturales). A temperatura ambiente en presencia de iones $\mathrm{Ca}^{2+}$ y a la elevada alcalinidad $(\mathrm{pH}=12)$ que se genera en la hidratación del cemento portland, los silicatos en forma vítrea que contienen las cenizas volantes llegan a cristalizar formando silicatos cálcicos de baja basicidad, de gran estabilidad hidráulica, que aportan resistencias mecánicas e impermeabilidad a los hormigones y morteros que contienen estos vidrios.

\subsection{Cementos}

\subsubsection{Fabricación}

Todos los cementos han sido obtenidos en la misma instalación por molturación conjuntá de sus componentes: clínker, yeso y, en su caso, cenizas volantes.

La instalación consta de un molino tubular de $13 \mathrm{~m}$ de longitud y $3,5 \mathrm{~m}$ de diámetro, que trabaja en circuito cerrado con elevador de cangilones y un clasificador de partículas Va equipado con tres básculas dosificadoras gravimétricas para la alimentación de los materiales (clínker, yeso y cenizas volantes), y de una báscula para pesar el caudal de material que por estar insuficientemente molido retorna al molino procedente del separador. El molino va provisto de un "oído eléctrico", aparato que mediante la medida del nivel de ruido en la primera cámara, regula la cantidad de alimentación, con el fin de que en todo momento el nivel de sonido en dicha primera cámara permanezca constante.

Hemos realizado 10 ensayos que abarcan desde enero de 1971 a marzo de 1972 . Los ensayos se hicieron tomando la muestra después de asegurarse que se habían alcanzado las condiciones de trabajo deseadas, en lo cual se empleaban más de 24 horas para cada uno de los tipos de cemento.

La finura necesaria en cada caso se logra regulando la velocidad en el plato dispersor del clasificador de tamaños.

\subsubsection{Cementos obtenidos}

4.3.2.1. Cemento portland puro P-450-ARI (según RC-75). Constituido por el clínker de cemento portland (descrito en 4.2.1.) y la cantidad de piedra de yeso crudo (descrita en 4.2.2.) necesaria para regular el fraguado.

\subsubsection{Cemento portland con adiciones activas PA-350 (según RC-75)}

Se regularon las básculas con el fin de obtener un cemento con un porcentaje de cenizas de aproximadamente el $13 \%$. La relación yeso/clínker fue aproximadamente la misma que en el cemento portland P-450-ARI. 
4.3.2.3. Cemento puzolánico PUZ-II-350 (según RC-75)

Se regularon las básculas con el fin de obtener un cemento con un porcentaje de cenizas de aproximadamente $23 \%$. La relación yeso/clínker la hemos mantenido aproximadamente igual que en el cemento portland puro P-450-ARI.

La finura necesaria fue la misma que en el caso del cemento portland puro P-450-ARI.

\section{PARTE EXPERIMENTAL}

\subsection{Propiedades de los materiales de partida}

\subsubsection{Clínker. Análisis químico y composición potencial}

El análisis químico (según PCCH-64, apartado 2.7.) del clínker fabricado durante el período que duró el estudio (de enero de 1971 a marzo de 1972) ha sido (valores medios de casi 200 muestras):

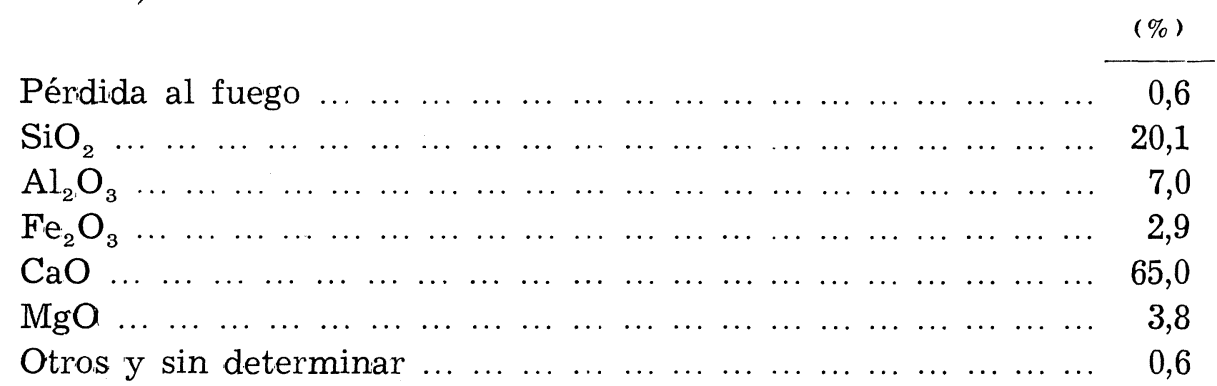

La composición potencial, según Bogue (4), calculada a partir de estos valores obtenidos en el análisis química resulta:

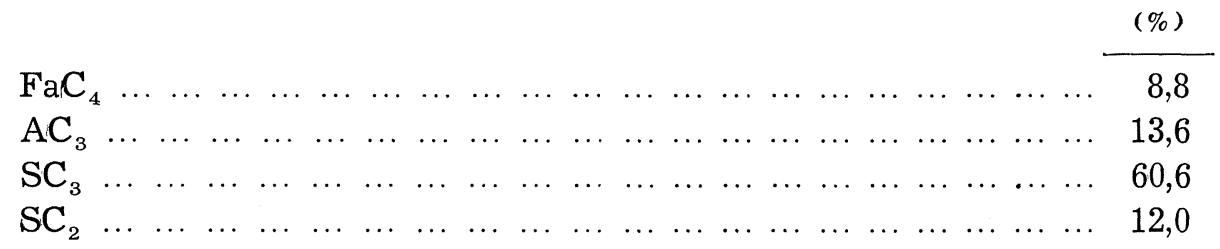

El índice de saturación de cal es del $98 \%$.

\subsubsection{Piedra de yeso}

La piedra de yeso crudo utilizada para regular el fraguado del cemento tiene una riqueza de aproximadamente el $84 \%$ en $\mathrm{SO}_{4} \mathrm{Ca} .2 \mathrm{H}_{2} \mathrm{O}$.

\subsubsection{Cenizas volantes. Características químicas y granulometría}

El análisis químico medio (realizado según PCCH-64, apartado 2.7) fue:

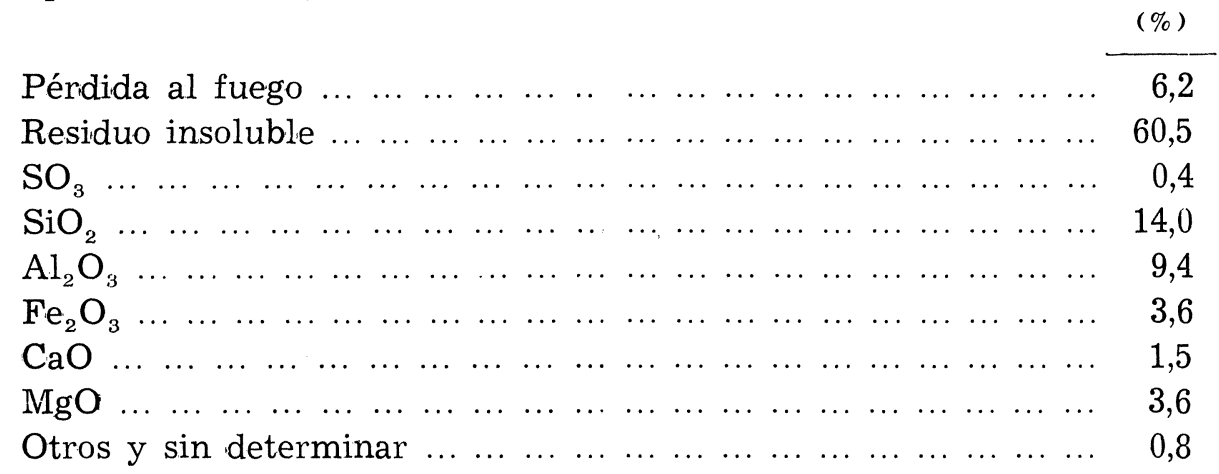


La granulometría se determinó con una tamizadora Alpine, que trabaja por barrido de aire.

Los resultados medios obtenidos fueron:

\begin{tabular}{ccc}
\hline $\begin{array}{c}\text { Tamiz } \\
(\text { mallas/cm }\end{array}$ & $\begin{array}{c}\text { Luz de malla del tamiz } \\
\text { (en micras) }\end{array}$ & $\%$ retenido \\
\hline 900 & 200 & 0,2 \\
2.500 & 120 & 1,6 \\
4900 & 90 & 3,7 \\
10.000 & 60 & 10,7 \\
16.900 & 45 & 19,8 \\
27.225 & 35 & 38,6 \\
\hline
\end{tabular}

\subsection{Propiedades de los cementos}

5.2.1. Análisis químico (según PCCH-64, apartado 2.7.)

\begin{tabular}{lcrr}
\hline & P-450-ARI (\%) & PA-350 (\%) & PUZ-II-350 (\%) \\
\hline Pérdida al fuego & 3,4 & 3,3 & 4,0 \\
Residuo insoluble & 0,3 & 8,0 & 12,9 \\
$\mathrm{SO}_{3}$ & 3,2 & 2,7 & 2,3 \\
$\mathrm{SiO}_{2}$ & 19,6 & 19,4 & 19,1 \\
$\mathrm{Al}_{2} \mathrm{O}_{3}$ & 6,8 & 7,7 & 8,6 \\
$\mathrm{Fe}_{2} \mathrm{O}_{3}$ & 2,5 & 2,8 & 3,1 \\
$\mathrm{CaO}$ & 60,8 & 52,3 & 46,5 \\
$\mathrm{MgO}$ & 3,2 & 3,0 & 2,9 \\
Otros y sin determinar & 0,2 & 0,8 & 0,6 \\
\hline
\end{tabular}

\subsubsection{Densidad real (según PCCH-64, apartado 2.3.)}

Se determinó en un volumenómetro de Le Chatelier utilizando como líquido auxiliar benzol.

Valores medios $\left(\mathrm{en} \mathrm{g} / \mathrm{cm}^{3}\right)$ :

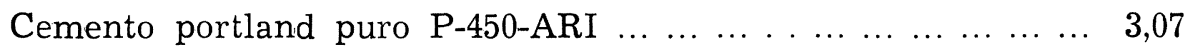

Cemento portland con adiciones activas PA-350 $\ldots \ldots \ldots \ldots \ldots c k$

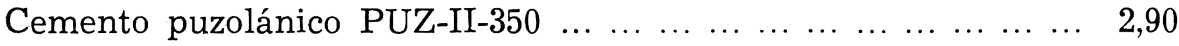

\subsubsection{Superficie específica Blaine (según PCCH-64, apartado 2.2.).}

Utilizamos ftalato de butilo como líquido manométrico.

El peso de cada tipo de cemento necesario para llenar la célula es función del peso específico real del mismo (punto 5.2.2.) y operamos en todos los casos con una porosidad de $0,500 \pm 0,005$. Los resultados obtenidos han sido:

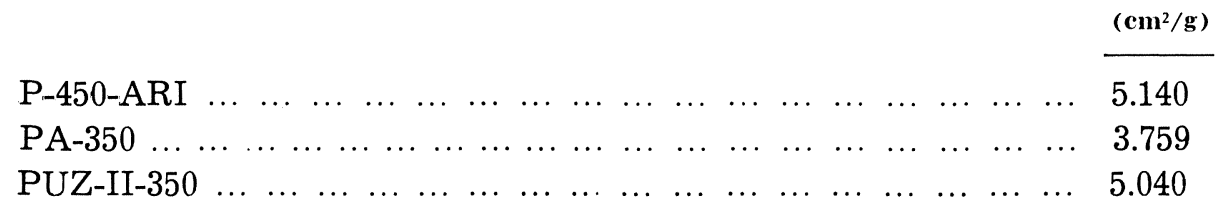




\subsubsection{Finura de molido}

Se determinó por dos métodos:

\subsubsection{Por chorro de aire}

Se ha realizado en una tamizadora Alpine, que trabaja por barrido de aire. El tamiz de menor luz de malla ha sido el de 25 micras.

\begin{tabular}{|c|c|c|c|c|}
\hline $\begin{array}{l}\text { Luz de malla } \\
\text { (en micras) }\end{array}$ & P-450-ARI & $\begin{array}{c}\% \text { retenido en cada } \\
\text { PA-350 }\end{array}$ & la tamiz & PUZ-11-350 \\
\hline 120 & 0 & 0 & $\ldots$ & 0 \\
\hline 90 & 0 & 0,4 & & 0 \\
\hline 60 & 0,1 & 3,4 & & 0,2 \\
\hline 45 & 2,0 & 10,5 & & 1,9 \\
\hline 35 & 7,4 & 21,7 & & 8,3 \\
\hline 25 & 15,7 & 31,6 & 1 & 15,6 \\
\hline
\end{tabular}

El cemento P-450-ARI y el cemento PUZ-II-350 se molieron a una finura prácticamente equivalente. La producción del molino ha alcanzado una media de $17 \mathrm{t} / \mathrm{h}$.

El cemento PA-350 se molió más grueso, siendo la producción del molino aproximadamente $30 \mathrm{t} / \mathrm{h}$.

\subsubsection{Por sedimentación}

Hemos utilizado dos pipetas de Andreasen, cuya forma y dimensiones se indican en la figura 2.

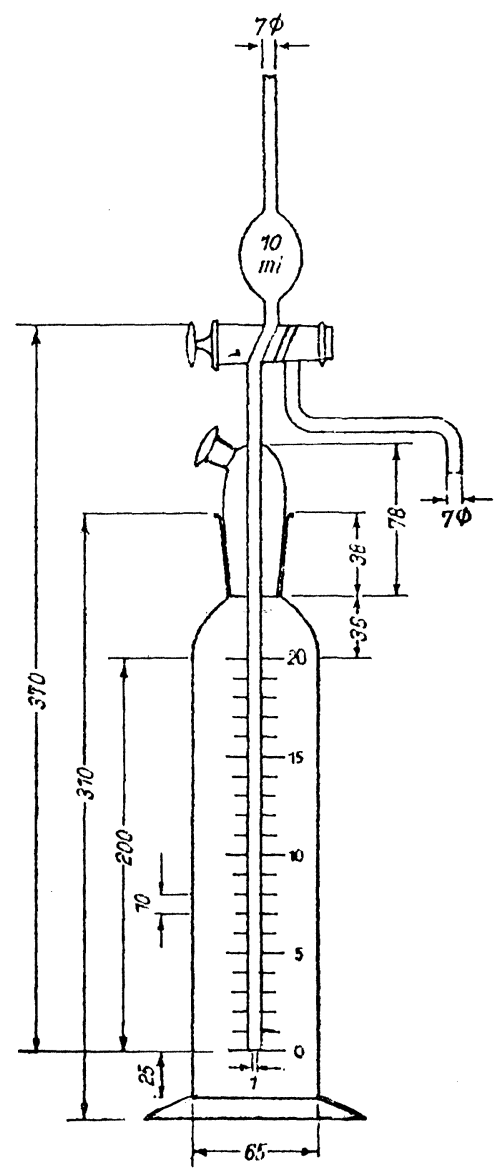

Fig. 2.- ripeta normal según Andreasen (medidas en mmt). 
El tarado y contraste de ambas pipetas se realizó según el método descrito en el Heft 33 , "Mahl Feinheit Von Zement. Richtlinien Für Die Bestimmung" (10).

El cálculo de los tiempos al cabo de los que tomamos las distintas muestras lo realizamos aplicando la ecuación de la Ley de Stokes:

$$
T=\frac{18 \cdot \eta \cdot H}{980 d^{2}\left(D_{1}-D_{2}\right)}
$$

donde:

$T=$ tiempo al cabo del que debe tomarse la muestra (en segundos).

$\eta=$ viscosidad cinemática (en centipoises).

$H=$ altura de caída (en $\mathrm{cm}$ ).

$d=$ diámetro de las partículas (en micras).

$D_{1}=$ densidad de la muestra a ensayar $\left(\mathrm{en} \mathrm{g} / \mathrm{cm}^{3}\right)$.

$D_{2}=$ densidad del líquido utilizado como medio de sedimentación (en $\mathrm{g} / \mathrm{cm}^{3}$ ).

La altura de caída inicial fue en todos los casos $20 \mathrm{~cm}$. La concentración inicial utilizada, fue en todos los casos $0,5 \mathrm{~g} / 100 \mathrm{ml}$, y el peso necesario de producto para esa concentración viene dado por la ecuación:

$$
W_{0}=0,01 \cdot C_{0} \cdot V_{\mathrm{H}}
$$

donde:

$W_{0}=$ peso de la sustancia necesario (en g).

$C_{0}=$ concentración inicial $(\mathrm{en} \mathrm{g} / 100 \mathrm{ml})$.

$V_{\mathrm{H}}=$ volumen del cilindro de la pipeta de Andreasen (en $\mathrm{m} l$ ) entre la marca de contraste y la altura de caída elegida, $20 \mathrm{~cm}$.

Tiempos al cabo de los cuales tomamos la muestra en cada uno de los tipos de cemento:

\begin{tabular}{cccr}
\hline $\begin{array}{c}\text { Diámetro de partículas } \\
\text { (en micras) }\end{array}$ & Tiempo de toma de muestms & $\begin{array}{c}\text { (seg) } \\
\text { PA-350 }\end{array}$ & PUZ-I1-350 \\
\hline 40 & 416 & 441 & 786 \\
30 & 721 & 763 & 1.784 \\
20 & 1.632 & 1.728 & 3.171 \\
15 & 2.899 & 3.070 & 11.149 \\
8 & 10.194 & 10.792 & 456 \\
\hline
\end{tabular}

Operamos en todos los casos con la densidad real indicada en el punto 5.2.2.

Granulometrías obtenidas

\begin{tabular}{cccc}
\hline $\begin{array}{c}\text { Diámetro de particulas } \\
\text { (en micras) }\end{array}$ & P-450-ARI & $\begin{array}{c}\text { retenido } \\
\text { PA-350 }\end{array}$ & PUZ-II-350 \\
\hline 40 & 7,1 & & 78,4 \\
30 & 13,3 & 28,4 & 7,0 \\
20 & 33,2 & 49,4 & 38,3 \\
15 & 43,3 & 60,6 & 50,2 \\
8 & 65,3 & 78,8 & 71,2 \\
\hline
\end{tabular}


5.2.4.3. En las figuras 3,4 y 5 representamos gráficamente los valores medios de los resultados obtenidos (fig. 3, cemento P-450-ARI; fig. 4, cemento PA-350 y fig. 5, cemento PUZ-II-350).

Podemos observar en trazo fino la curva correspondiente a los resultados obtenidos con la tamizadora Alpine, y en trazo grueso la de los obtenidos por sedimentación.

En la zona común a ambos trazos (25 a 40 micras) se observa que, sistemáticamente, los valores obtenidos por sedimentación indican un grado de finura ligeramente menor ( 2 a $3 \%)$.

5.2.5. Expansión al autoclave (según PCCH-64, apartado 2.5.)

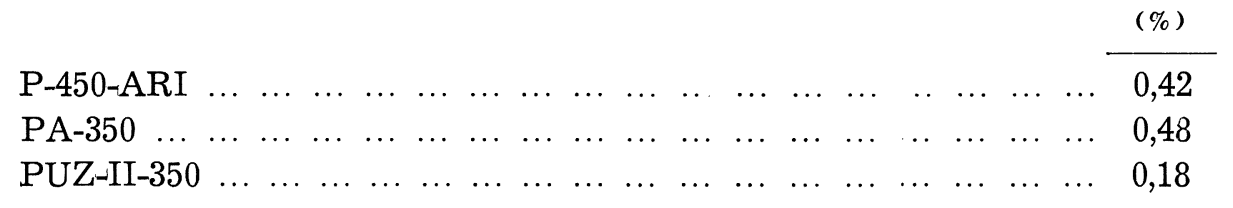

\subsubsection{Valor puzolánico}

\subsubsection{Según $\mathrm{PCCH}-64$, apartado 2.733 (temperatura $40^{\circ} \mathrm{C}$ y edad 7 y 28 días)}

La alcalinidad total se determinó utilizando $\mathrm{ClH} 1 \mathrm{~N}$ y anaranjado de metilo como indicador. El contenido en $\mathrm{CaO}$ por precipitación con oxalato amónico, y posterior calcinación a óxido cálcico.

Edad 7 días

\begin{tabular}{lcc}
\hline & $\begin{array}{c}\text { Alcalinidad total } \\
\text { (milimoles/litro) }\end{array}$ & $\begin{array}{c}\text { Cao } \\
\text { (milimoles/litro) }\end{array}$ \\
\hline P-450 ARI & 73,7 & 7,6 \\
FA-350 & 64,8 & 6,5 \\
PUZ-II-350 & 63,1 & 5,1 \\
\hline
\end{tabular}

Edad 28 días

\begin{tabular}{lcc}
\hline & $\begin{array}{c}\text { Alcalinidad total } \\
\text { (milimoles/litro) }\end{array}$ & $\begin{array}{c}\text { Cao } \\
\text { (milimoles/litro) }\end{array}$ \\
\hline P-450 ARI & 74,6 & 6,8 \\
PA-350 & 72,3 & 4,4 \\
PUZ-II-350 & 74,3 & 3,3 \\
\hline
\end{tabular}

Cada pareja de valores representa un punto en la gráfica de la figura 6. La Norma indica que un cemento es puzolánico cuando el punto representativo del mismo queda por debajo de la curva de solubilidad de la cal $-\mathrm{CaO}$ - en presencia de álcalis (representada en la gráfica).

El hecho de que un punto se sitúe por debajo de la curva, a una edad del ensayo más corta o más larga ( 7 ó 28 días, según la Norma), es función de la cantidad de adición (cenizas volantes en este caso) y de la calidad de la misma. 


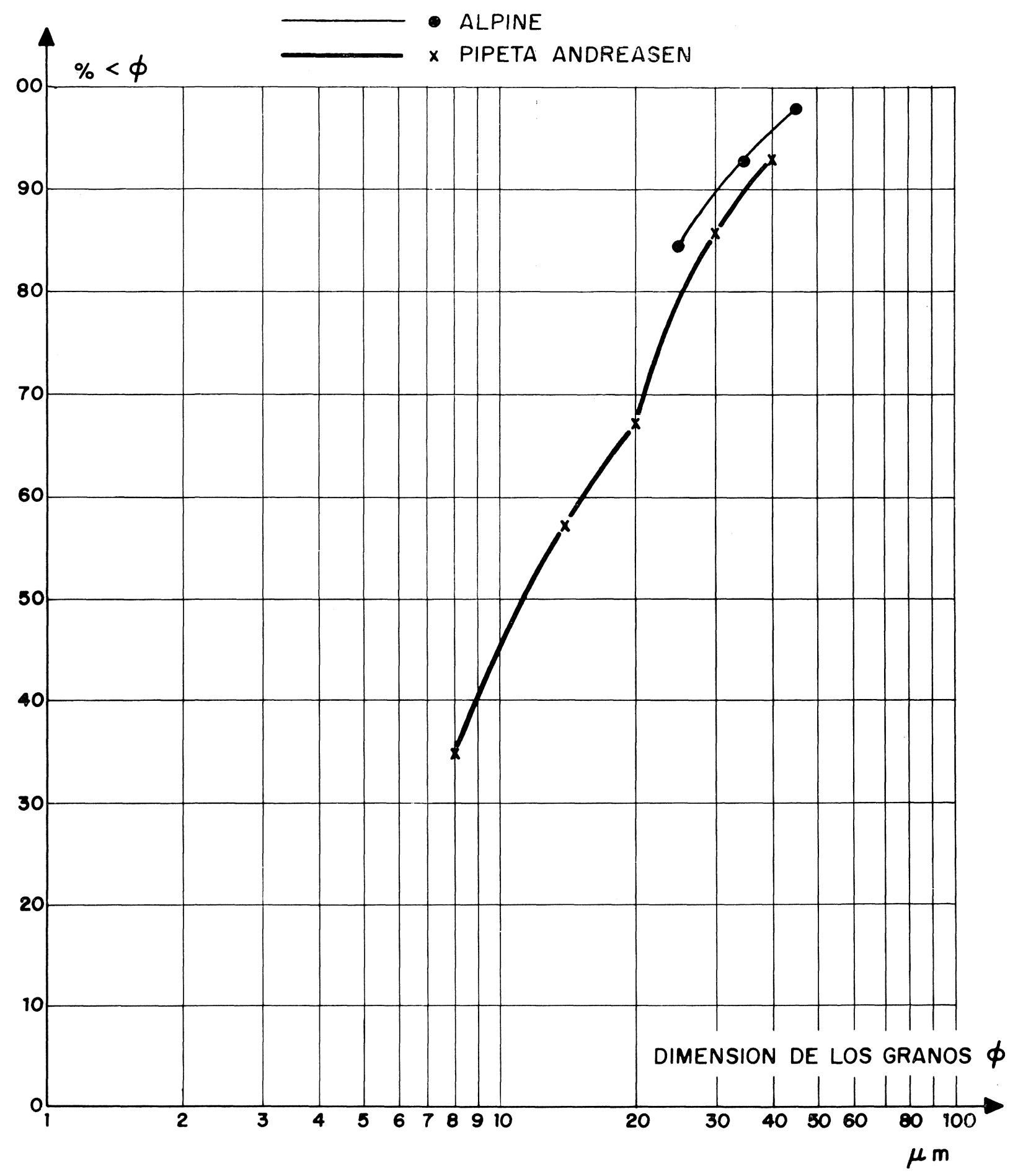

Fig. 3 
GEMENTOAPA-3 E

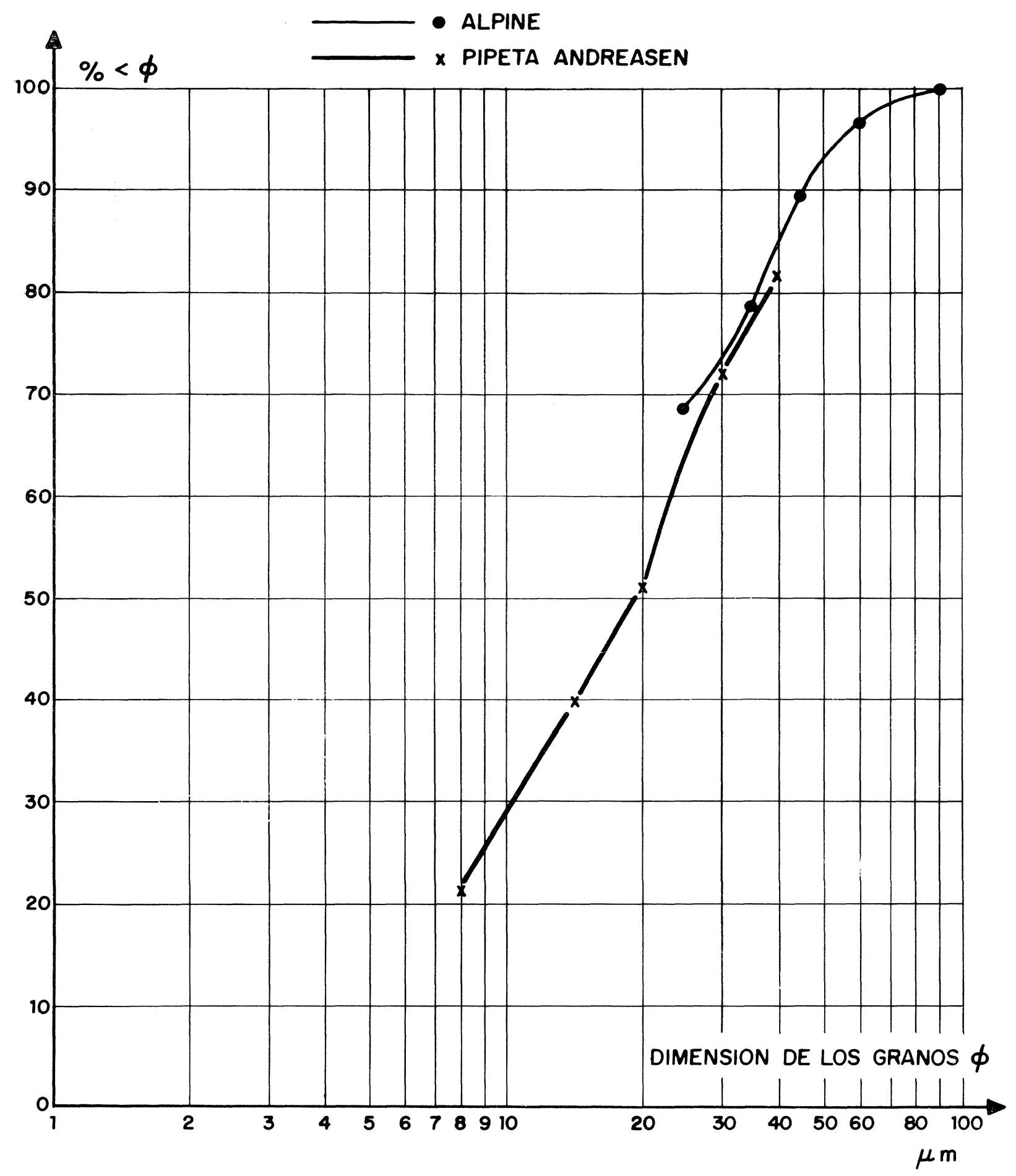

Fig. 4

34 


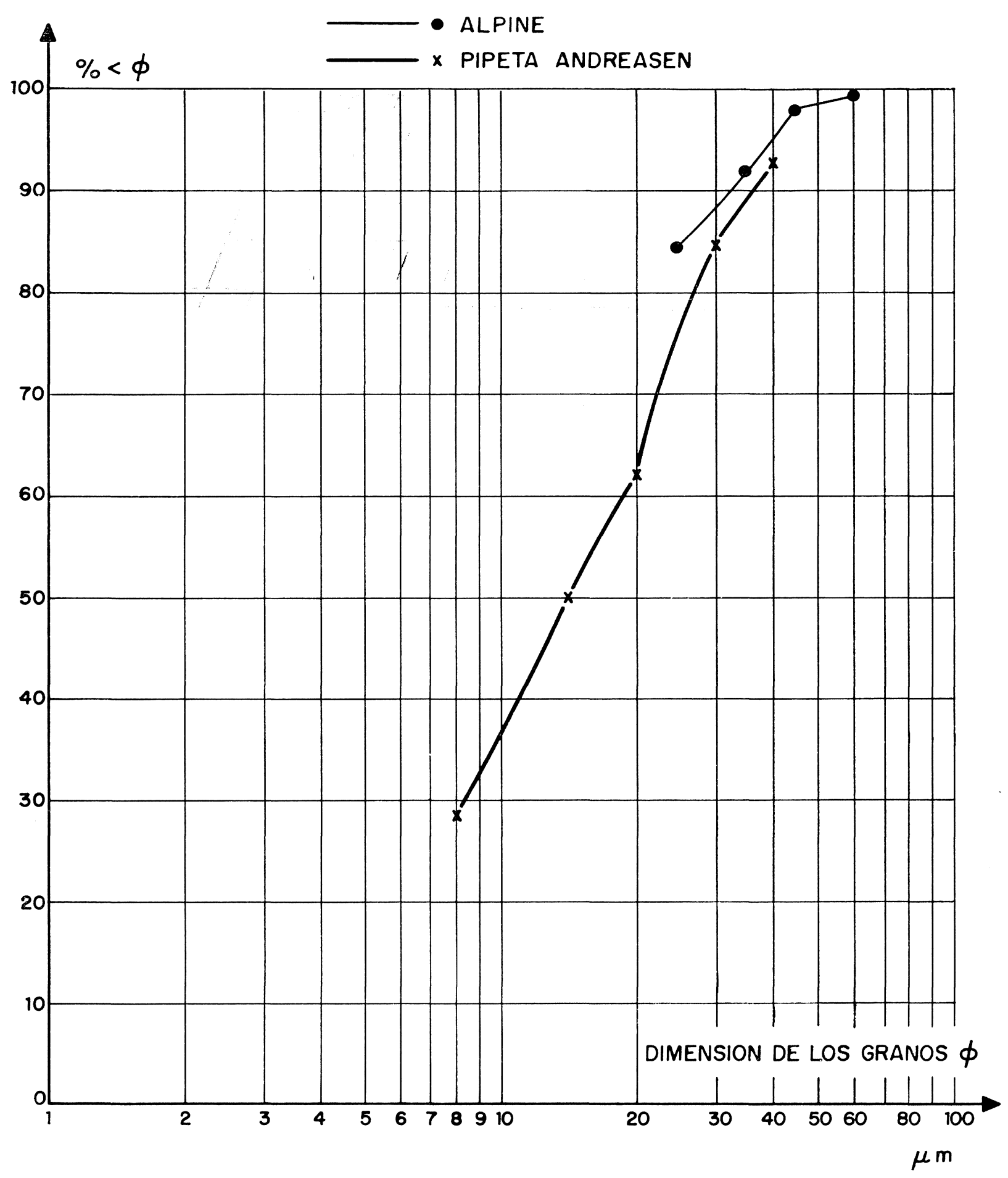

Fig. -5 


\section{ENGAYO DE PUZOLANITIDAD SEGUN FRATINI}

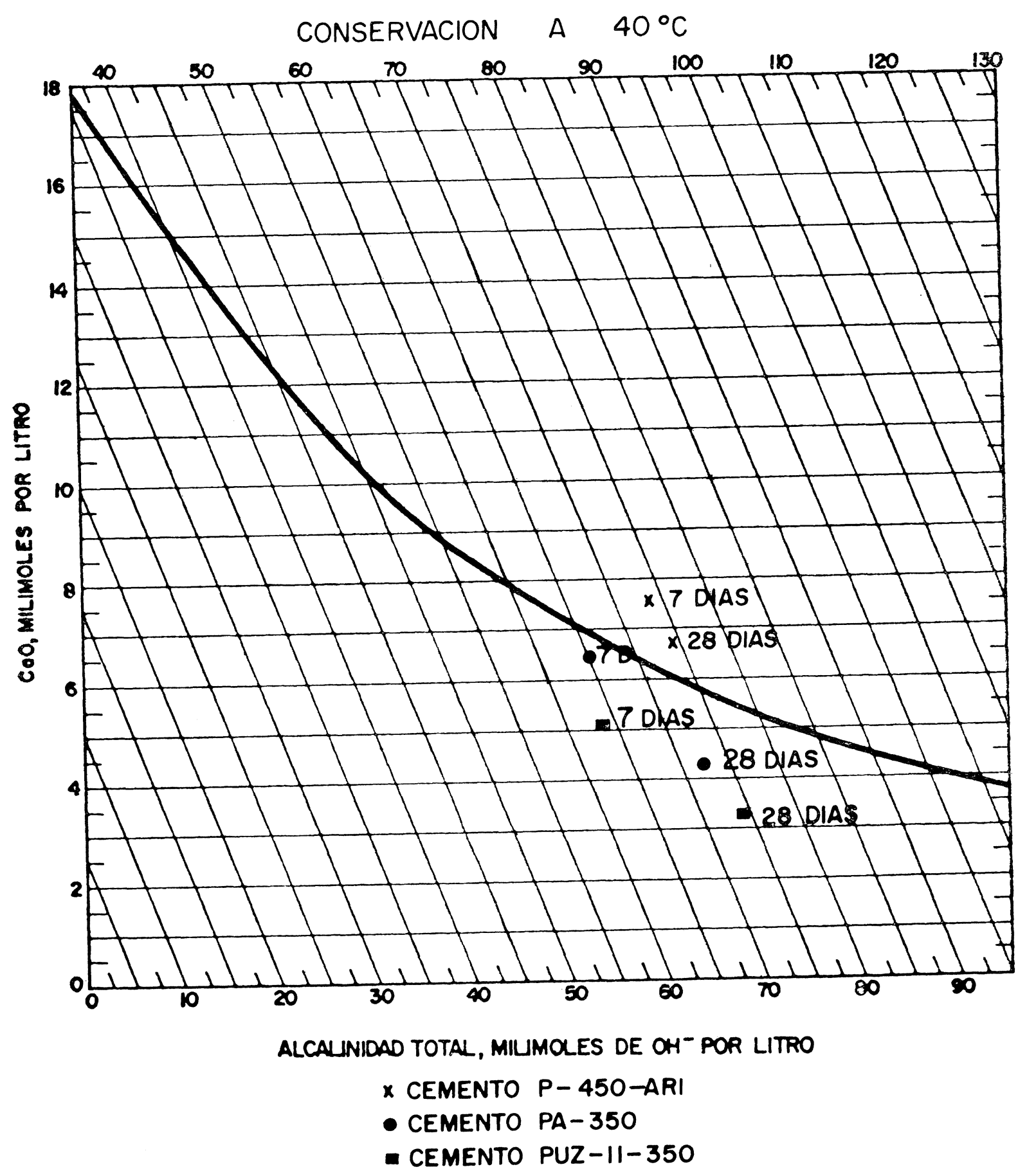

Fig. 6 
5.2.6.2. Además es interesante conocer si la reacción de la cal iiberada con las cenizas volantes tiene lugar en condiciones distintas a las de la Norma.

Hemos intentado medir qué ocurría al variar dos condiciones del ensayo (temperatura y edad). Para ello, y siguiendo el mismo método operatorio, hemos dejado los erlenmeyer -que en el punto anterior se mantuvieron 7 y 28 días a $40^{\circ} \mathrm{C}$ - en la sala de curados de probetas (temperatura $20 \pm 2^{\circ} \mathrm{C}$ ) durante 6 meses y 1 año. Hemos determinado los mismos parámetros que en el punto 5.2.6.1.

Edad 180 días/temperatura $20^{\circ} \mathrm{C}$

\begin{tabular}{lcc}
\hline & $\begin{array}{c}\text { Alcalinidad total } \\
\text { (milimoles/litro) }\end{array}$ & $\begin{array}{c}\text { Cao } \\
\text { (milimoles/litro) }\end{array}$ \\
\hline P-450-ARI & 82,9 & 8,9 \\
PA-350 & 76,6 & 6,0 \\
FUZ-II-350 & 77,1 & 4,9 \\
\hline
\end{tabular}

Edad 1 año/temperatura $20^{\circ} \mathrm{C}$

\begin{tabular}{lcc}
\hline & $\begin{array}{c}\text { Alcalinidad totai } \\
\text { (milimoles/litro) }\end{array}$ & $\begin{array}{c}\text { Cao } \\
\text { (milimoles/litro) }\end{array}$ \\
\hline P-450-ARI & 82,6 & 8,6 \\
PA-350 & 81,7 & 5,7 \\
PUZ-II-350 & 80,2 & 3,8 \\
\hline
\end{tabular}

Cada pareja de valores representa un punto en el gráfico de la figura. 7.

5.2.6.3. También hemos mantenido sometidos a las variaciones de la temperatura ambiente, en el jardín de llaboratorio, erlenmeyer hasta la edad de 6 meses y 1 año.

Edad 180 días/temperatura ambiente

\begin{tabular}{lcc}
\hline & $\begin{array}{c}\text { Alcalinidad total } \\
\text { (milimoles/litro) }\end{array}$ & $\begin{array}{c}\text { Cao } \\
\text { (milimoles/litro) }\end{array}$ \\
\hline P-450-ARI & 84,2 & 9,4 \\
PA-350 & 75,4 & 6,7 \\
PUZ-II-350 & 73,1 & 5,8 \\
\hline
\end{tabular}

Edad 1 año/temperatura ambiente

\begin{tabular}{lcc}
\hline & $\begin{array}{c}\text { Alcalinidad total } \\
\text { (milimoles/litro) }\end{array}$ & $\begin{array}{c}\text { Cao } \\
\text { (milimoles/litro) }\end{array}$ \\
\hline P-450-ARI & 84,1 & 8,8 \\
PA-350 & 78,7 & 6,4 \\
PUZ-II-350 & 79,4 & 5,0 \\
\hline
\end{tabular}

Cada pareja de valores representa un punto en el gráfico de la figura 8.

Podemos observar que, a todas las temperaturas estudiadas, la cal liberada en la hidratación del cemento reacciona con las cenizas volantes. 


\section{ENSAYO DE PUZOLANIGIDAD SEGUN FRATINI}

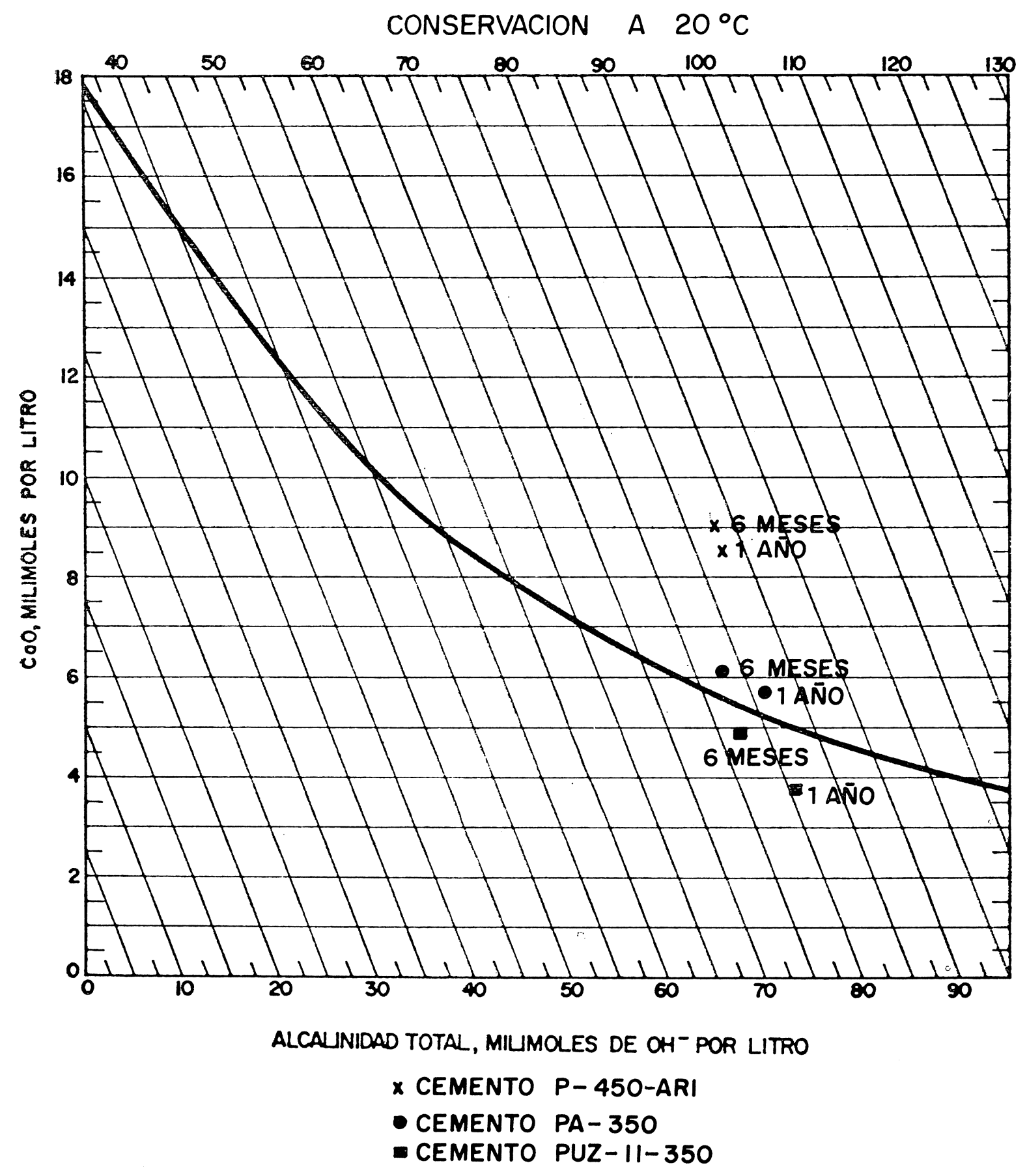

Fig. : 


\section{ENSAYOTE PUZOLANIEIDAD SEGUN FRATINI}

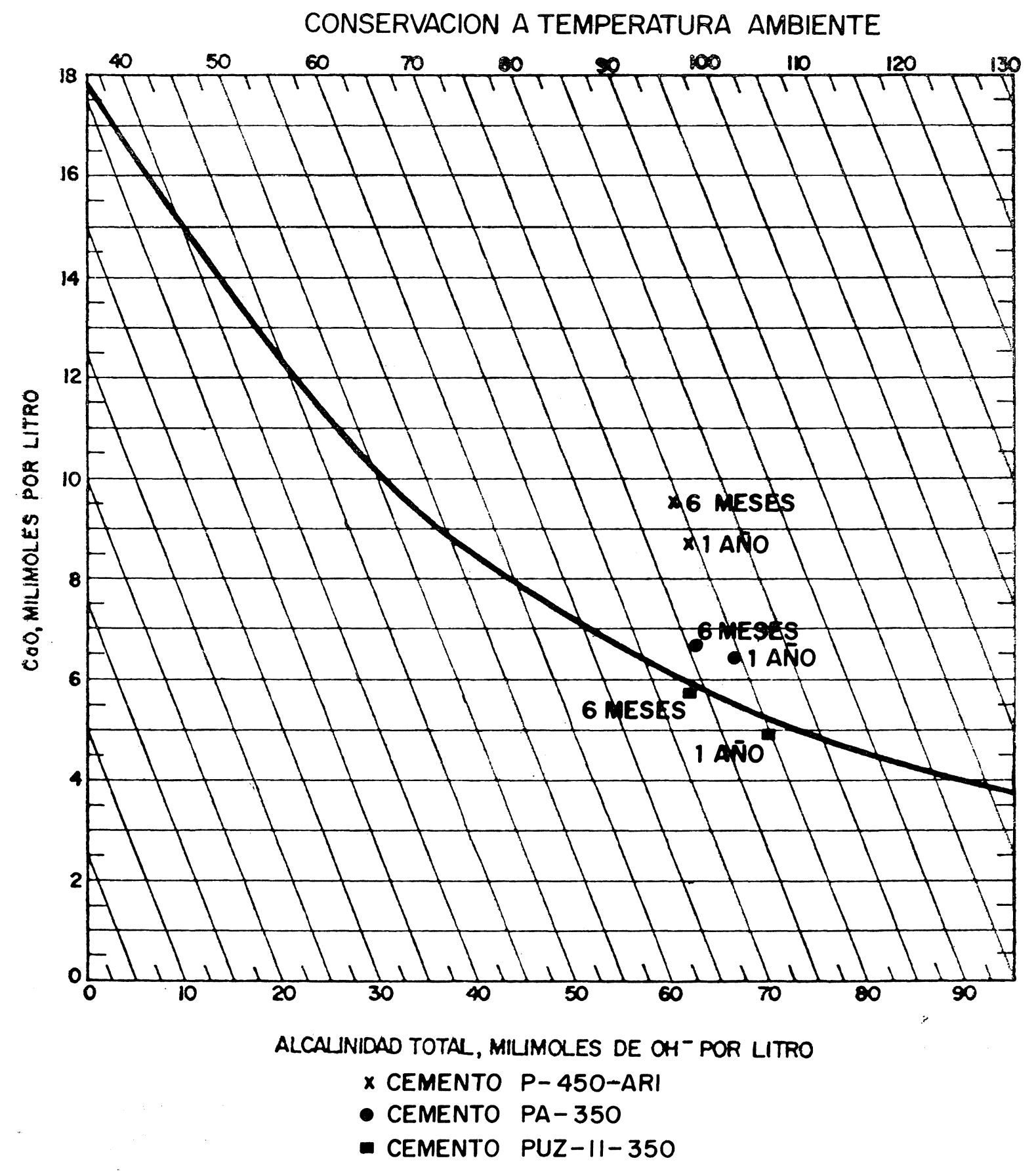

Fig. 8 
Se necesita más tiempo a medida que la temperatura es menor. En estudios en curso de realización conoceremos el grado de reacción que tiene lugar, a temperatura ambiente, a la edad de 2 años.

\subsection{Características y propiedades de los morteros de estos cementos}

\subsubsection{Preparación}

En cada ensayo, y para la muestra de cemento PA, se ha preparado el mortero normalizado (relación cemento/arena $=1 / 3$, y relación $a / c=0,5$ ) descrito en $\mathrm{PCCH}-64$, apartado 2.6.1.5. Se ha medido el esparcimiento en la mesa de sacudidas (según PCCH-64, apartado 2.6.2.4.) alcanzándose un valor medio de $79 \%$. Los morteros de los cemertos P-450ARI y PUZ-II-350 se prepararon ateniéndose en todo a la Norma PCCH-64, a excepción del agua de amasado, que se añadió en las cantidades necesarias para lograr esparcimientos en la tabla de sacudidas semejantes a los del mortero del cemento PA.

Relaciones $a / c$ necesarias para cada tipo de cemento, y esparcimientos medios alcanzados:

\begin{tabular}{|c|c|c|}
\hline & Relaciones a/c & Esparcimiento $(\%)$ \\
\hline P-450-ARI & 0,48 & 77 \\
\hline PUZ-II-350 & 0,49 & 79 \\
\hline
\end{tabular}

\subsubsection{Número de probetas}

Hemos conservado probetas para ensayar a las edades de $1,2,3,7,28,90$ y 180 días y a 1 , 2, 3 y 4 años, en diferentes medios de curado.

El número de probetas necesarias para cada cemento en cada ensayo ha sido de 39 , lo que totaliza en todo el trabajo casi 1.200 probetas prismáticas de $4 \times 4 \times 16 \mathrm{~cm}$.

\subsubsection{Arena}

Utilizamos en todos los ensayos arena normalizada (descrita en $\mathrm{PCCH}-64$, apartado 2.6.1.1.).

Es arena silícea, procedente de Segovia, lavada, separada por tamaños y recompuesta de tal forma que todos los gránulos sean inferiores a $2 \mathrm{~mm}$, y cuya granulometría está comprendidai entre las dos líneas de la figura 9. Es suministrada por el Instituto Eduardo Torroja de la Construcción y del Cemento.

\subsubsection{Agua de amasado}

La sistemática seguida para su determinación se describe en el punto 5.3.1.

\subsubsection{Condiciones de curado}

5.3.5.1. La Norma indica que las probetas preparadas para el ensayo de resistencia a flexotracción y compresión se mantendrán en una cámara a $21 \pm 2^{\circ} \mathrm{C}$ con más del $90 \%$ de humedad relativa, durante un período comorendido entre 20 y 28 horas después de fabricadas. Al cabo de este tiempo las probetas se desmoldan y se sumergen en agua que se mantiene a $20 \pm 2^{\circ} \mathrm{C}$.

40 
ZONA GRANULOMETRICA ADMISIBLE PARA LA ARENA

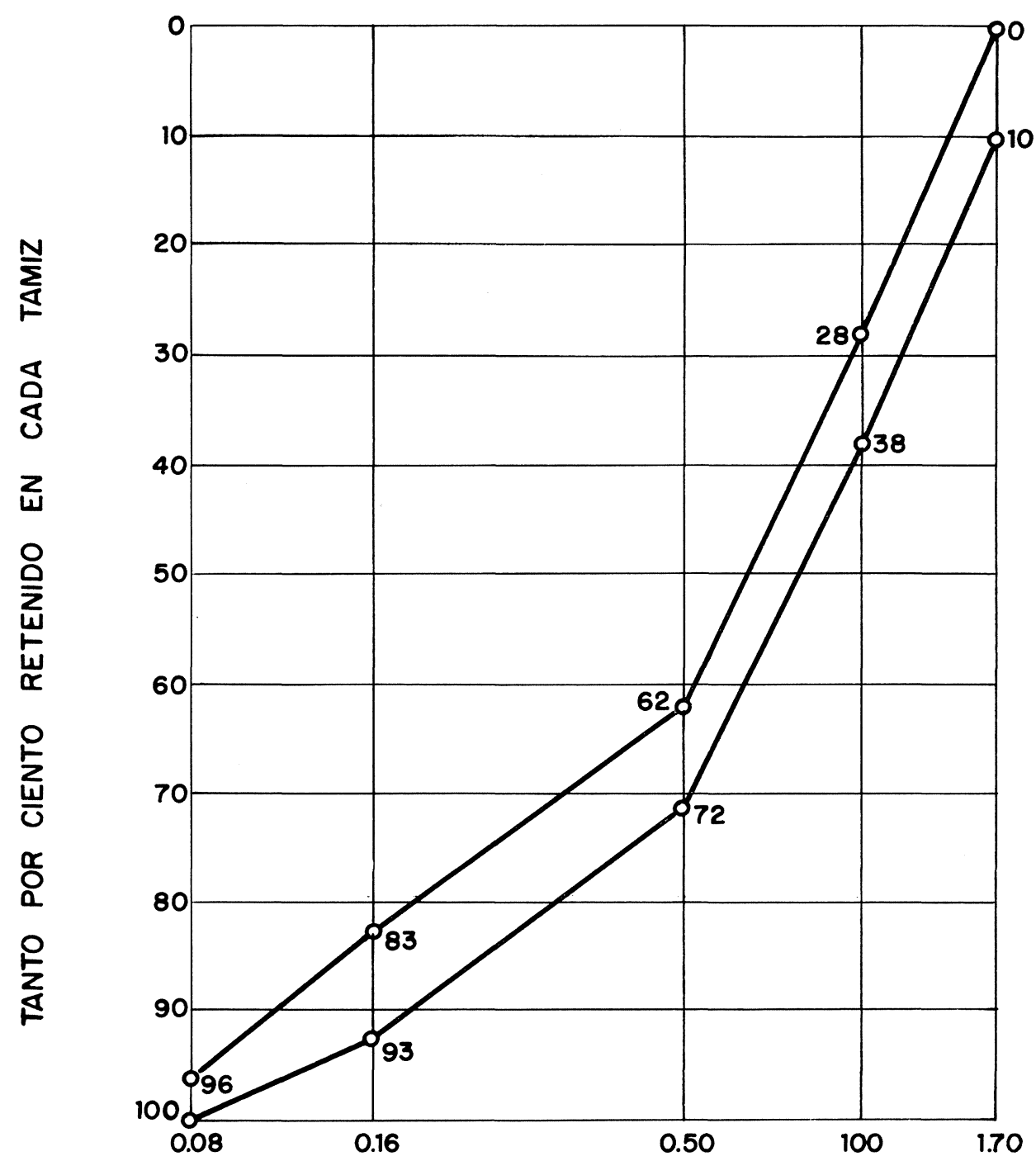

LUCES DE LOS TAMICES DE MALLA CUADRADA EN mm

Fig. 9 
5.3.5.2. Como quiera que las obras de hormigón no mantienen estas condiciones, hemos preiparado también probetas para ensayar a las mismas edades, pero en condiciones similares a las que los hormigones pueden verse sometidos en las obras como son:

- Agua a temperatura ambiente (en un recipiente mantenido en el exterior del laboratorio). El agua se cambia cada 3 meses aproximadamente. Están sometidas a las variaciones de la temperatura ambiente.

- En el aire ambiente (sometidas a la intemperie, lluvia, sol, etc.).

\subsubsection{Medios agresivos}

El agua del mar en el Atlántico contiene aproximadamente 2,5 g/litro de ion $\mathrm{SO}_{4}{ }^{=}$y 1,5 $\mathrm{g} /$ litro de ion $\mathrm{Mg}^{2+}$. En la bibliografía se encuentran muchos resultados de ensayos realizados por investigadores que someten las probetas a soluciones mucho más agresivas (concentraciones de $5 \%$ de $\mathrm{SO}_{4} \mathrm{Mg}$ ). Esta concentración ha sido elegida también por nosotros para el estudio de nuestros materiales (en dos ambientes):

- Solución de $\mathrm{SO}_{4} \mathrm{Mg}$ al $5 \%$ (mantenida en un recipiente en una cámara de temperatura controlada $+20 \pm 2^{\circ} \mathrm{C}$ ).

- Solución de $\mathrm{SO}_{4} \mathrm{Mg}$ al $5 \%$, mantenida a temperatura ambiente (en recipiente tapado situado en el exterior).

Eln ambos casos la solución se renueva cada 4 meses aproximadamente.

\subsubsection{Valor puzolánico}

Hemos determinado la diferencia de la aceleración del endurecimiento, en función del aumento de la temperatura (entre 20 y $50^{\circ} \mathrm{C}$ ), según el método propuesto por Lea (2).

Valores medios de las cargas máximas unitarias:

\begin{tabular}{|c|c|c|c|}
\hline & $\begin{array}{lllllll}\mathbf{F} & \mathbf{L} & \mathbf{E} & \mathbf{X} & \mathbf{O} & \mathbf{T} & \mathbf{R} \\
\end{array}$ & $\begin{array}{lllllll}\mathbf{R} & \mathbf{A} & \mathbf{C} & \mathbf{C} & \mathbf{I} & \mathbf{O} & \mathbf{N} \\
\end{array}$ & \\
\hline Cemento & $\begin{array}{c}\text { días en agua } 20^{\circ} \mathrm{C} \\
\left(\mathrm{en} \mathrm{kg} / \mathrm{cm}^{2}\right)\end{array}$ & $\begin{array}{c}5 \text { días en agua } 20^{\circ} \mathrm{C} \\
2 \text { días en agua } 50^{\circ} \mathrm{C} \\
\left(\mathrm{en} \mathrm{kg} / \mathrm{cm}^{2}\right)\end{array}$ & $\Delta$ \\
\hline P-450-ARI & 77 & 82 & +5 \\
\hline PA-350 & 65 & 92 & +27 \\
\hline \multirow[t]{2}{*}{ PUZ-11-250 } & 67 & 105 & +38 \\
\hline & $\begin{array}{lllll}\mathbf{C} & \mathbf{O} & \mathbf{M} & \mathbf{P} & \mathbf{R} \\
\end{array}$ & $\begin{array}{lllll}\mathbf{E} & \mathbf{S} & \mathbf{I} & \mathbf{O} & \mathbf{N} \\
\end{array}$ & \\
\hline Cemento & $\begin{array}{c}7 \text { dias en agua } 20^{\circ} \mathrm{C} \\
\left(\mathrm{en} \mathrm{kg} / \mathrm{cm}^{2}\right)\end{array}$ & $\begin{array}{c}5 \text { días en agua } 20^{\circ} \mathrm{C} \\
2 \text { días en agua } 50^{\circ} \mathrm{C} \\
\left(\mathrm{en} \mathrm{kg} / \mathrm{cm}^{2}\right)\end{array}$ & $\Delta$ \\
\hline P-450-ARI & 445 & 480 & $+\quad 35$ \\
\hline PA-350 & 315 & 419 & +104 \\
\hline PUZ-II-350 & 350 & 515 & +165 \\
\hline
\end{tabular}

Puede aprecianse un mayor aumento del valor de las resistencias a flexotracción y compresión del cemento que contiene mayor porcentaje de cenizas, respecto al cemento puro y al cemento con un contenido en cenizas intermedio, cuando las probetas son curadas 2 días en agua a $50^{\circ} \mathrm{C}$. Este es el principio en el que se basa el citado autor para considerar la utilidad de un determinado tipo o clase de adición para la fabricación de cementos. 
De la comparación de los resultados anteriores se puede deducir, colateralmente, la mayor aptitud de los cementos PUZ-II-350 y PA-350, por este orden, en relación con el cemento P-450-ARI, para su empleo en prefabricación de hormigón por tratamientos térmicos o higrotérmicos - con vapor libre, o a presión en autoclave- En efecto, la diferencia de "grado de madurez" del mortero (producto de la temperatura $-{ }^{\circ} \mathrm{C}-$ por el tiempo 一días-) con los dos tratamientos a $20^{\circ} \mathrm{C}$ y $50^{\circ} \mathrm{C}$ es, en todos los casos, de:

$$
\left(5 \text { días } \times 20^{\circ} \mathrm{C}\right)+\left(2 \text { días } \times 50^{\circ} \mathrm{C}\right)-\left(7 \text { días } \times 20^{\circ} \mathrm{C}\right)=60^{\circ} \mathrm{C} \text { día } .
$$

$\mathrm{Y}$, sin embargo, esa misma diferencia afecta muy desigualmente a los morteros de los tres cementos: el P-450-ARI, lógicamente el de mayor precio en el mercado, es el menos indicado técnicamente para dichos tratamientos. $\mathrm{El}$ más apto es, en efecto, el de mayor contenido de cenizas, el cual es, al mismo tiempo, el de propiedades y comportamiento puzolánicos. Este argumento apoya y complementa de hecho, desde otra vertiente tecnológica y práctica, el principio de Lea antes citado.

\subsubsection{Resistencias mecánicas}

Las probetas de mortero descritas en los puntos 5.3.1. y 5.3.2. y conservadas en los distintos medios de curado descritos en 5.3.5., al ensayarlas a flexotracción y compresión han dado los resultados que presentamos en la tabla siguiente.

\subsection{7.a.1.) Resistencias a flexotracción (en $\left.\mathrm{kg} / \mathrm{cm}^{2}\right)$}

I) Medio de conservación: Agua a $20^{\circ} \mathrm{C}$.

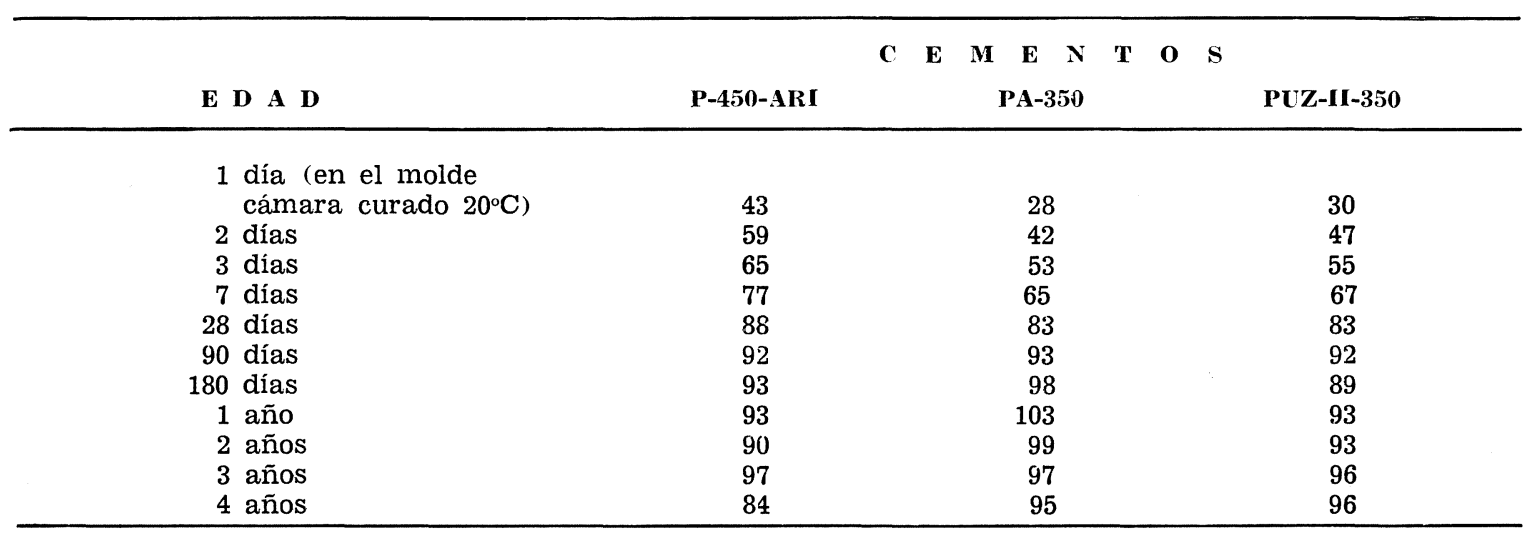

II) Medio de conservación: Agua a temperatura ambiente.

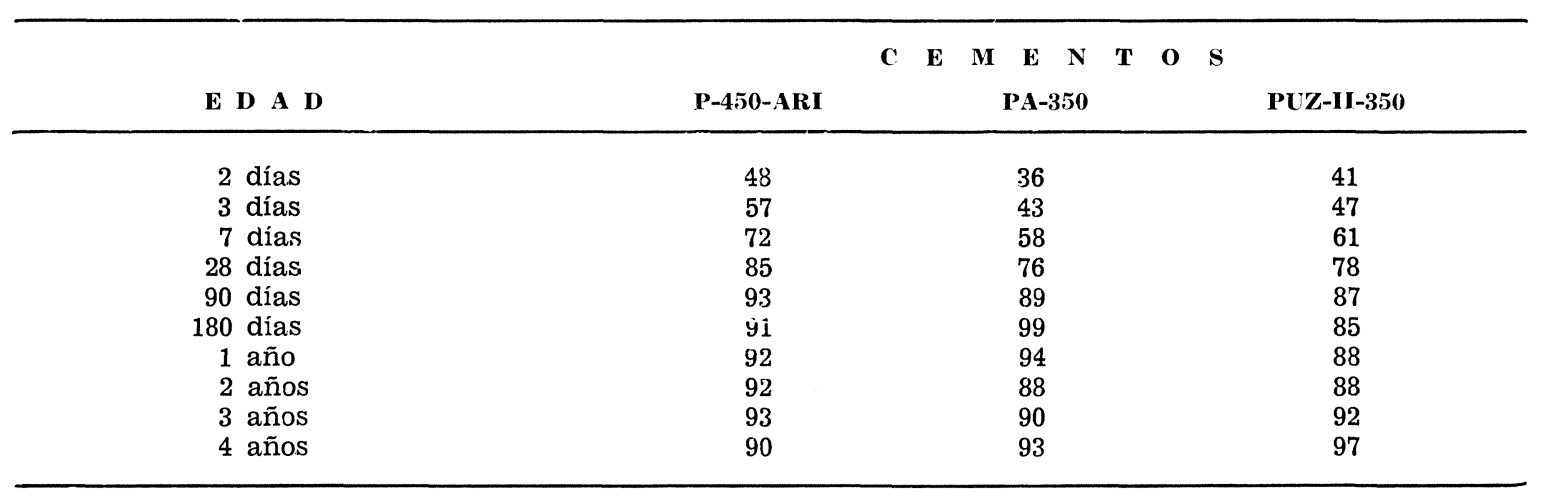


III) Medio de conservación: Aire a temperatura ambiente.

\begin{tabular}{ccccc}
\hline & $\begin{array}{c}\text { C } \\
\text { E D A }\end{array}$ & P-450-ARI & $\begin{array}{c}\text { T } \\
\text { PA-350 }\end{array}$ & PUZ-II-350 \\
\hline 3 días & 53 & 41 & 45 \\
7 días & 62 & 52 & 53 \\
28 días & 71 & 68 & 70 \\
90 días & 95 & 88 & 93 \\
180 días & 115 & 98 & 113 \\
1 año & 100 & 107 & 94 \\
2 años & 103 & 98 & 93 \\
3 años & 109 & 104 & 97 \\
4 años & 127 & 116 & 106 \\
\hline
\end{tabular}

Dada la elevada relación superficie/volumen de las probetas que ensayamos, la carbonatación superficial en este medio a edades avanzadas. influye mucho en los resultados del ensayo de resistencias a flexotracción y compresión.

En efecto, cabe precisar, por otra parte, que a igualdad de relación (grande) superficie/volumen de las probetas, se ven más afectadas, en primer lugar, las conservadas al aire ambiente, puesto que la carbonatación bajo agua es prácticamente nula; y, en segundo lugar, las probetas de cemento P-450-ARI, el cual, por ser de clínker de más alta saturación de cal y no contener ceniza, da mayor cantidad de cal de hidrólisis que, al no ser fijada por acción puzolánica, es capaz de carbonatarse más y más fácilmente.

Al cemento P-450-ARI le siguen en este aspecto los cementos PA-350 y PUZ-II-350, por este mismo orden y muy próximos entre sí, coincidiendo con el orden de menor a mayor contenido de ceniza en cada uno de ellos. Esto se puede materializar de alguna manera y en parte, en los valores de las columnas precedentes, aunque quede imprecisa la posible influencia de la variable finura, menor en el cemento PA-350 que en los otros dos.

\subsection{7.a.2.) Resistencia a aguas agresivas}

En estos medios agresivos los primeros resultados de resistencia son valores a 1 año, ya que a primeras edades el efecto de dichas soluciones sobre los morteros de cualesquiera de los cementos es prácticamente nulo y los valores serían similares a los obtenidos en agua.

I) Medio de conservación: $\mathrm{SO}_{4} \mathrm{Mg}$ al $5 \%$ conservado a $20^{\circ} \mathrm{C}$.

\begin{tabular}{|c|c|c|c|}
\hline $\begin{array}{llll}\text { E D A } & \text { D }\end{array}$ & $\begin{array}{c}C \\
\text { P-450-.1RI }\end{array}$ & $\begin{array}{cc}\text { T } & 0 \\
\text { PA-350 }\end{array}$ & PUZ-II-350 \\
\hline $\begin{array}{l}1 \text { año } \\
2 \text { años } \\
3 \text { años } \\
4 \text { años }\end{array}$ & $\begin{array}{l}93 \\
48 \\
36 \\
26\end{array}$ & $\begin{array}{l}97 \\
52 \\
26 \\
20\end{array}$ & $\begin{array}{r}102 \\
91 \\
76 \\
70\end{array}$ \\
\hline
\end{tabular}

II) Medio de conservación: $\mathrm{SO}_{4} \mathrm{Mg}$ al $5 \%$ conservado a temperatura ambiente.

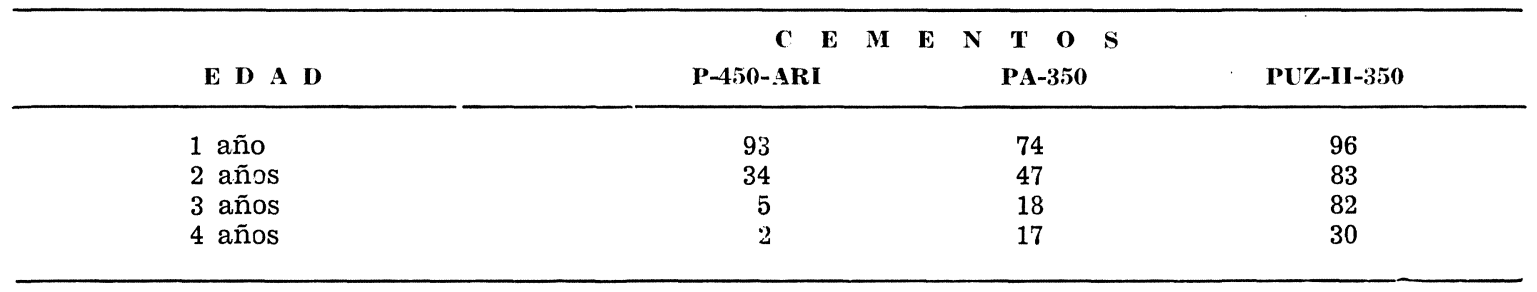

44 


\subsection{7.b.1.) Resistencia a compresión}

1) Medio de conservación: Agua a $20^{\circ} \mathrm{C}$.

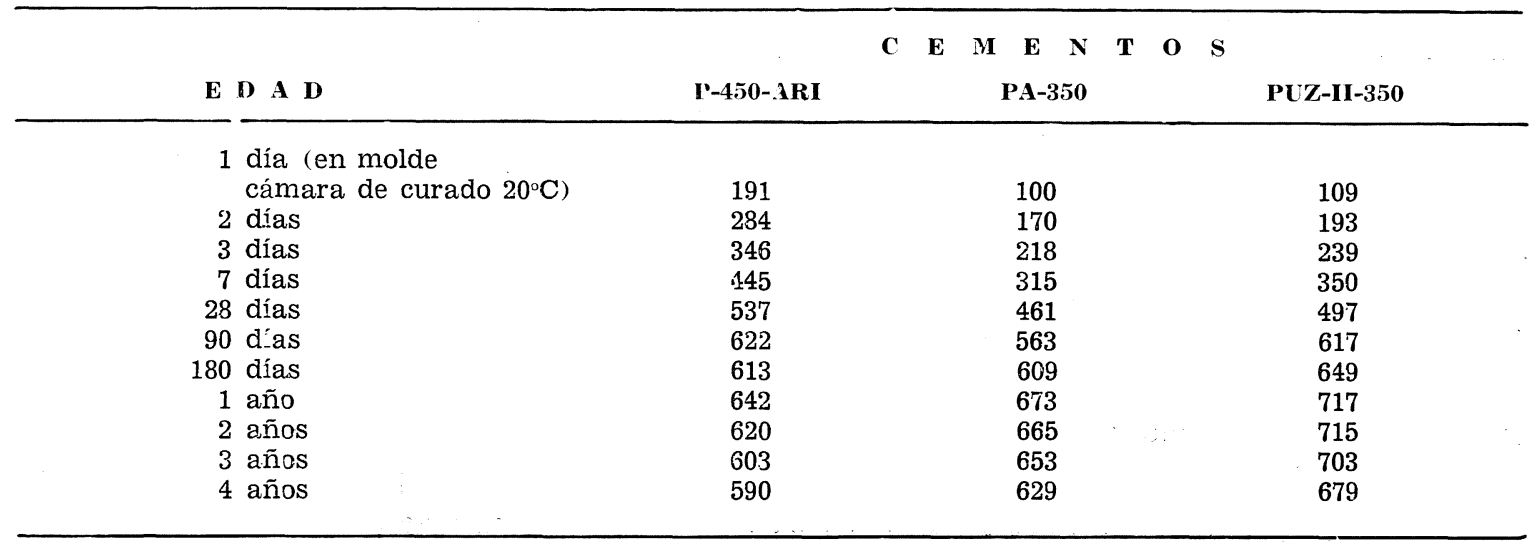

II) Medio de conservación: Agua a temperatura ambiente.

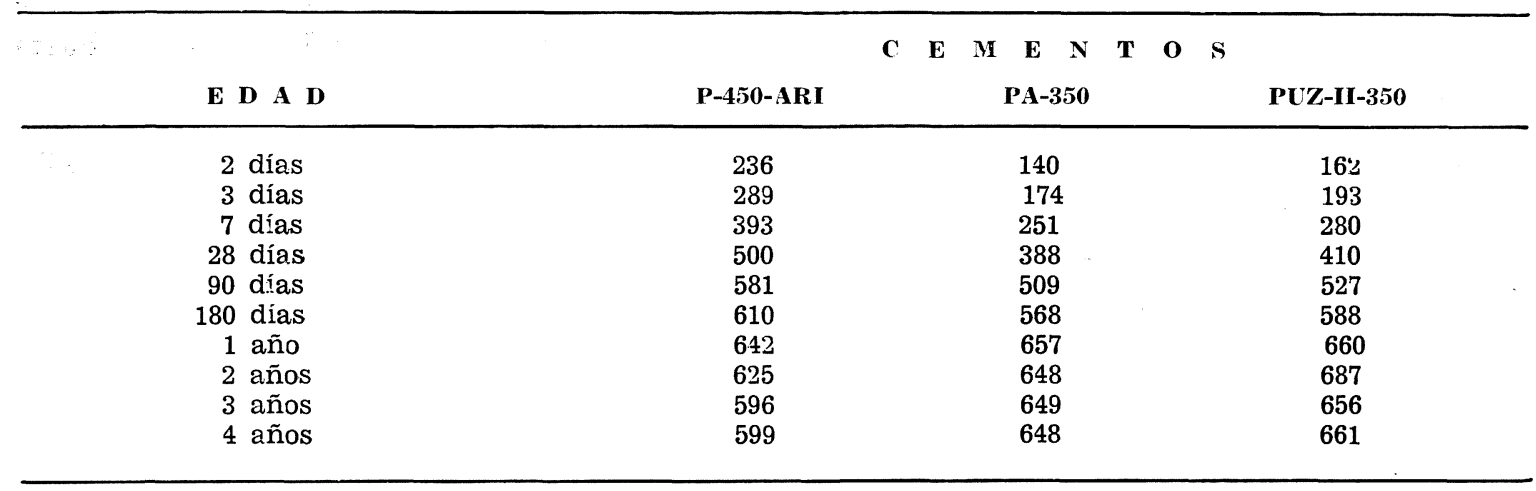

III) Medio de conservación: Aire a temperatura ambiente.

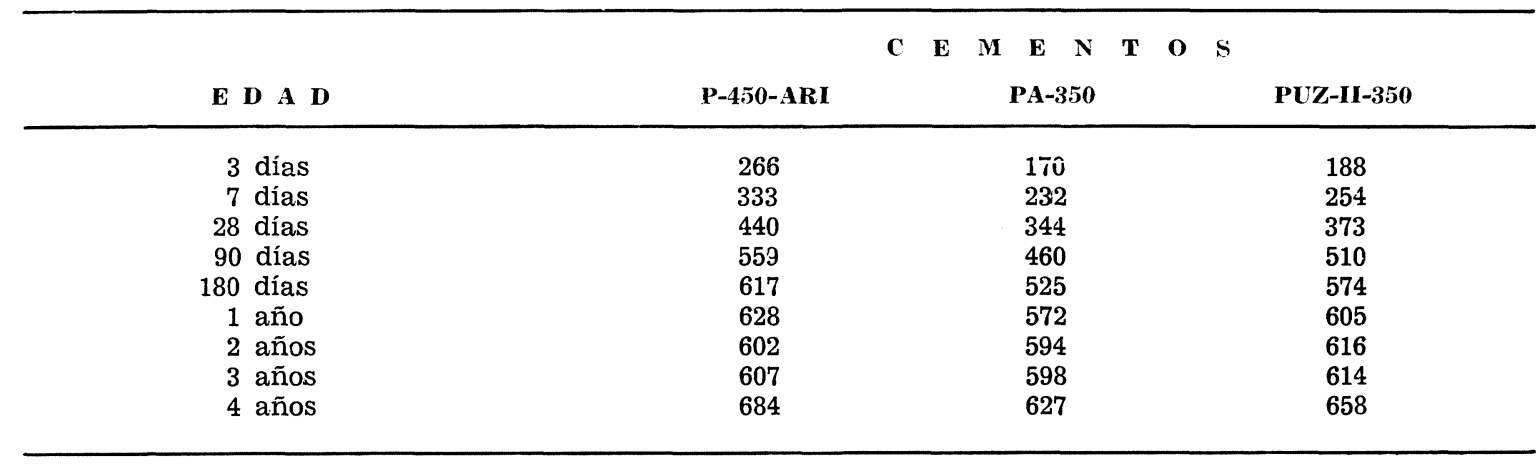

\subsection{7.b.2.) Resistencia a aguas agresivas}

I) Medio de conservación: $\mathrm{SO}_{4} \mathrm{Mg}$ al $5 \%$ conservado a $20^{\circ} \mathrm{C}$.

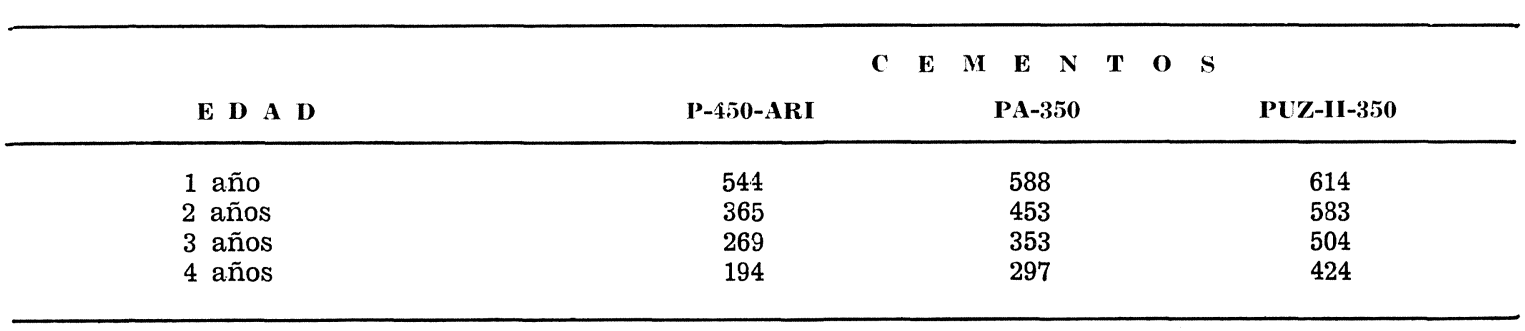


II) Medio de conservación: $\mathrm{SO}_{4} \mathrm{Mg}$ al $5 \%$ conservado a temperatura ambiente.

\begin{tabular}{lcccc}
\hline & & C E & I E N T O S & \\
E D A D & P-450-ARI & PA-350 & PUZ-II-350 \\
\hline 1 año & 510 & 474 & 600 \\
2 años & 335 & 443 & 537 \\
3 años & 81 & 168 & 492 \\
4 años & 49 & 125 & 325 \\
\hline
\end{tabular}

$\mathrm{Si}$ se calculan las relaciones entre las resistencias a la compresión de los cementos PUZ-II-350 y PA-350, correspondientes a los puntos 5.3.7.b.1.) y 5.3.7.b.2.), se podrá apreciar que dichas relaciones presentan un valor, prácticamente constante a todas las edades, comprendido entre 1,00 y 1,15 , con un promedio próximo a 1,10 , para conservaciones en agua y al aire. Esto, que denota en tales casos marchas paralelas del endurecimiento de ambos cementos en dichas condiciones, no se da en las relacionesi entre las resistencias de los cementos PA-350 y P-450-ARI, o PUZ-II-350 y P-450-ARI, si no es a partir de 180 días, 1 ó 2 años, según el medio de conservación. Esto indica marchas de endurecimiento distintas de los cementos PA-350 y PUZ-II-350, en relación con el cemento PA-450-ARI, hasta dichas edades y según las conservaciones.

En cambio, se podrá apreciar también que las relaciones entre las resistencias a compresión de! los cementos PA-350 y P-450-ARI por una parte, y de los cementos PUZ-II-350 y P-45a-ARI por otra, con conservación en sulfato magnésico a partir de un año, son continuamente crecientes, lo cual indica el mejor comportamiento de los cementos con ceniza respecto del que no la tiene. Pero eso se observa también en las correspondientes relaciones de los cementos PUZ-II-350 y PA-350 calculadas con los resultados de los respectivos cuadros de valores, lo que prueba, además, el mejor comportamiento del cemento PUZ-II-350 (verdaderamente puzolánico) respecto del cemento PA-350 (no puzolánico) frente al sulfato magnésico, y mejor aún en condiciones ambientales de conservación. Esta sería otra forma de "visualizar" la influencia de la puzolanicidad.

5.3.8. Representación gráfica de las resistencias mecánicas a compresión de los cementos PA-350 y PUZ-II-350 referida al cemento P-450-ARI

En las tablas que damos a continuación, así como en las gráficas en las que se representan esos valores, damos a la resistencia mecánica del cemento P-450-ARI el valor 1.

En la tabla, la primera columna corresponde a los cocientes obtenidos al dividir a cada edad y en cada condición las resistencias mecánicas del cemento PA-350 por las del cemento P-450-ARI; la segunda columna de la tabla corresponde a los cocientes obtenidos al dividir a cada edad y en cada condición las resistencias mecánicas del cemento PUZ-II350 por las del cemento P-450-ARI

En las gráficas, la línea de trazos representa los valores de la primera columna de la tabla; mientras que la línea continua representa los de la segunda columna.

El eje de abscisas es en todas las gráficas igual y, por comodidad de la representación, las distancias son iguales entre las distintas edades.

El eje de ordenadas es distinto para cada medio de curado. El motivo es que los valores de estos cocientes de las resistencias de los cementos PA y PUZ respecto a las del cemento puro $\mathrm{P}$ en los medios agresivos y a edades avanzadas, crecían de manera importante, siendo necesario ajustar la escala en cada caso.

46 
5.3.8.1. Medio de conservación: Agua a $20^{\circ} \mathrm{C}$

\begin{tabular}{lcc}
\hline EDAD & I & II \\
\hline 1 día & 0,52 & 0,57 \\
2 días & 0,60 & 0,68 \\
3 dias & 0,63 & 0,69 \\
7 días & 0,71 & 0,79 \\
28 días & 0,86 & 0,93 \\
90 días & 0,91 & 0,99 \\
\hline & & \\
\hline & & II \\
\hline EDAD & I & 1,06 \\
\hline 180 días & 0,99 & 1,12 \\
1 año & 1,05 & 1,15 \\
2 años & 1,07 & 1,17 \\
3 años & 1,08 & 1,15 \\
4 años & 1,07 & \\
\hline
\end{tabular}

Estos valores se representan en la figura 10.

5.3.8.2. Medio de conservación: Agua a temperatura ambiente.

\begin{tabular}{rcc}
\hline EDAD & I & II \\
\hline 2 días & 0,59 & 0,69 \\
3 días & 0,60 & 0,67 \\
7 días & 0,64 & 0,71 \\
28 días & 0,78 & 0,82 \\
90 días & 0,88 & 0,91 \\
180 días & 0,93 & 0,96 \\
1 año & 1,02 & 1,03 \\
2 años & 1,04 & 1,10 \\
3 años & 1,09 & 1,10 \\
4 años & 1,08 & 1,10 \\
& & \\
\hline
\end{tabular}

Estos valores se representan en la figura 11.

5.3.8.3. Medio de conservación: Aire a temperatura ambiente.

\begin{tabular}{rcc}
\hline EDAD & I & II \\
\hline 3 días & 0,64 & 0,71 \\
7 días & 0,70 & 0,76 \\
28 días & 0,78 & 0,85 \\
90 días & 0,82 & 0,91 \\
180 días & 0,85 & 0,93 \\
1 año & 0,91 & 0,96 \\
2 años & 0,99 & 1,02 \\
3 años & 0,99 & 1,01 \\
4 años & 0,92 & 0,96 \\
\hline
\end{tabular}

Estos valores se representan en la figura 12. 


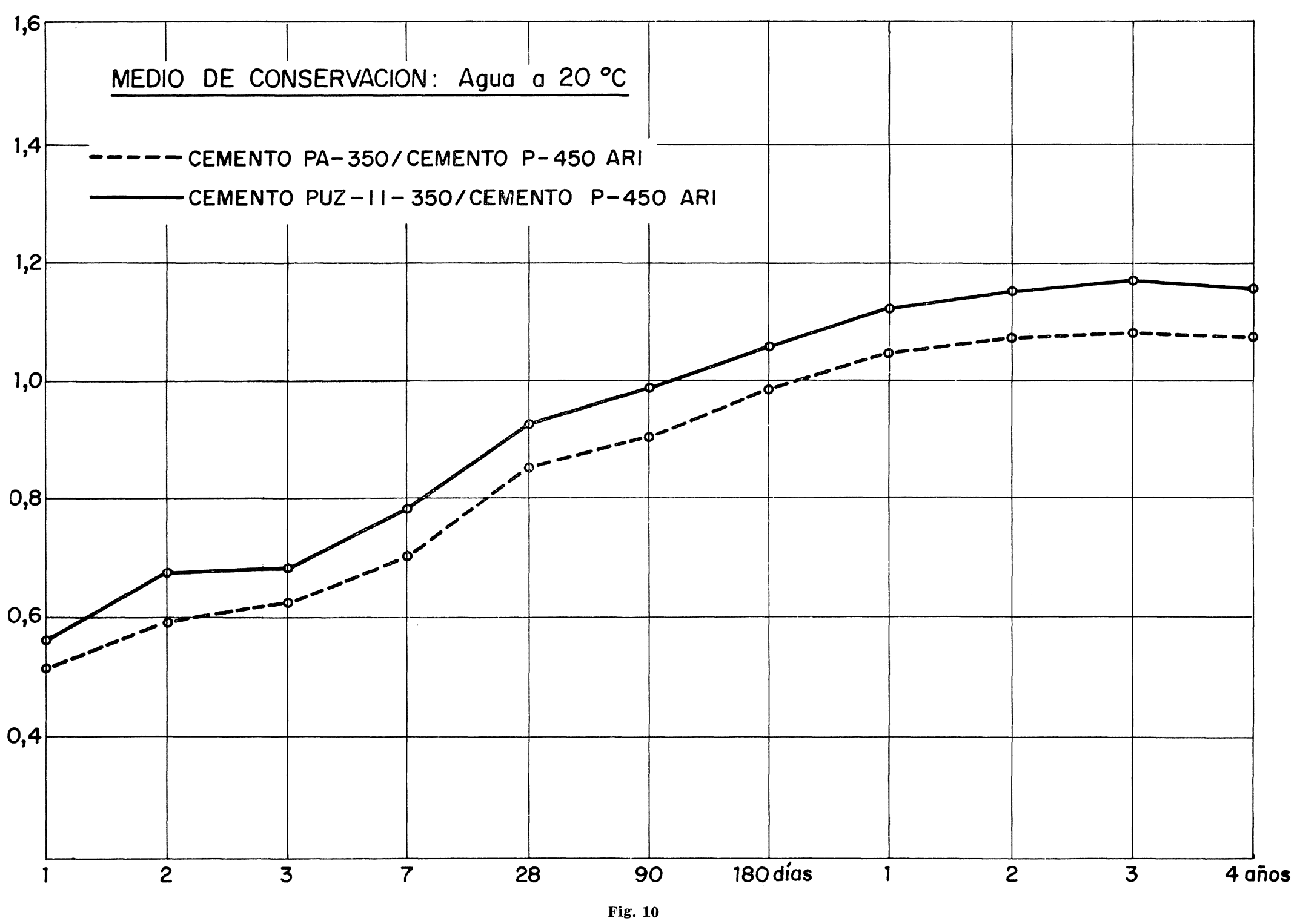




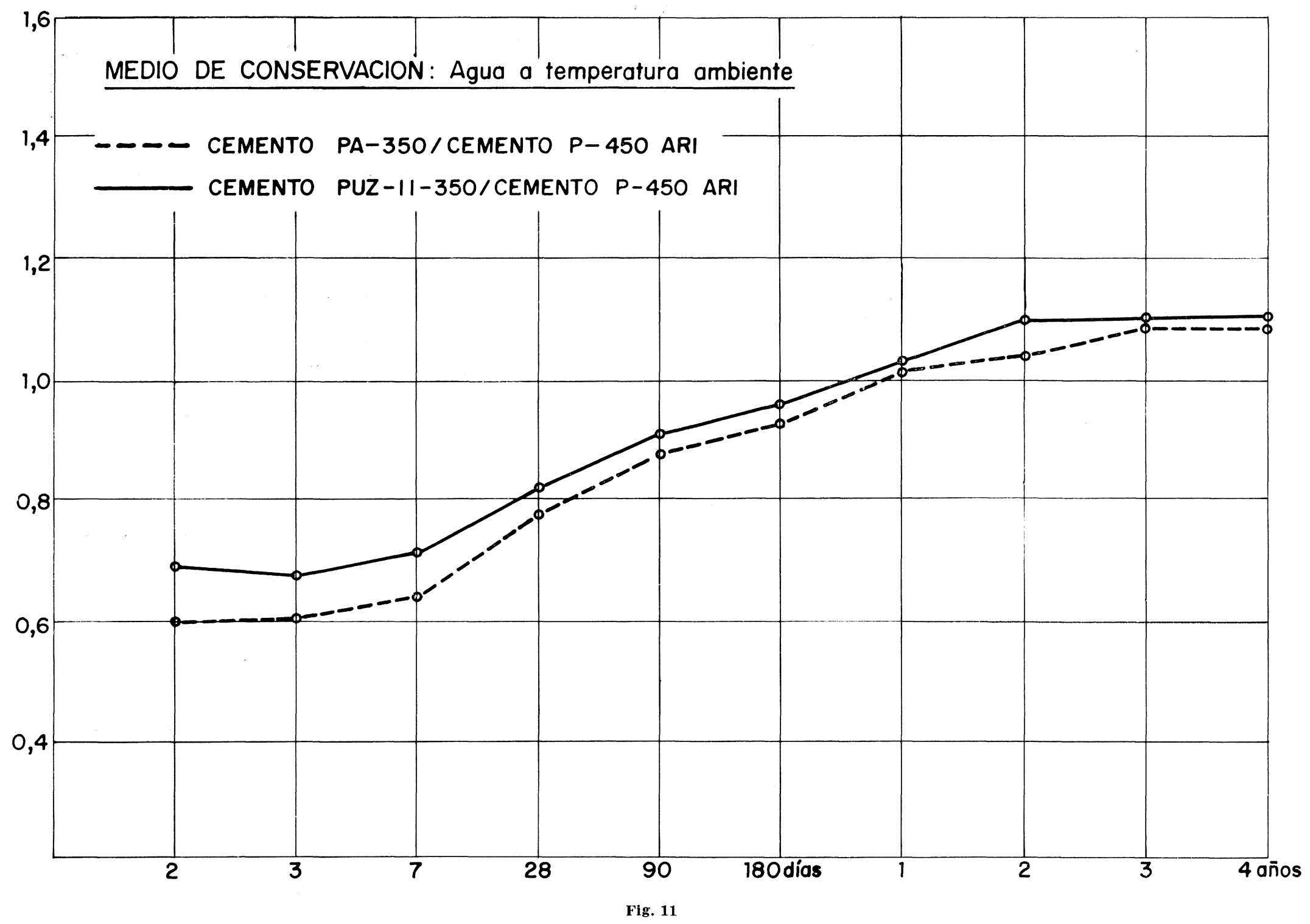




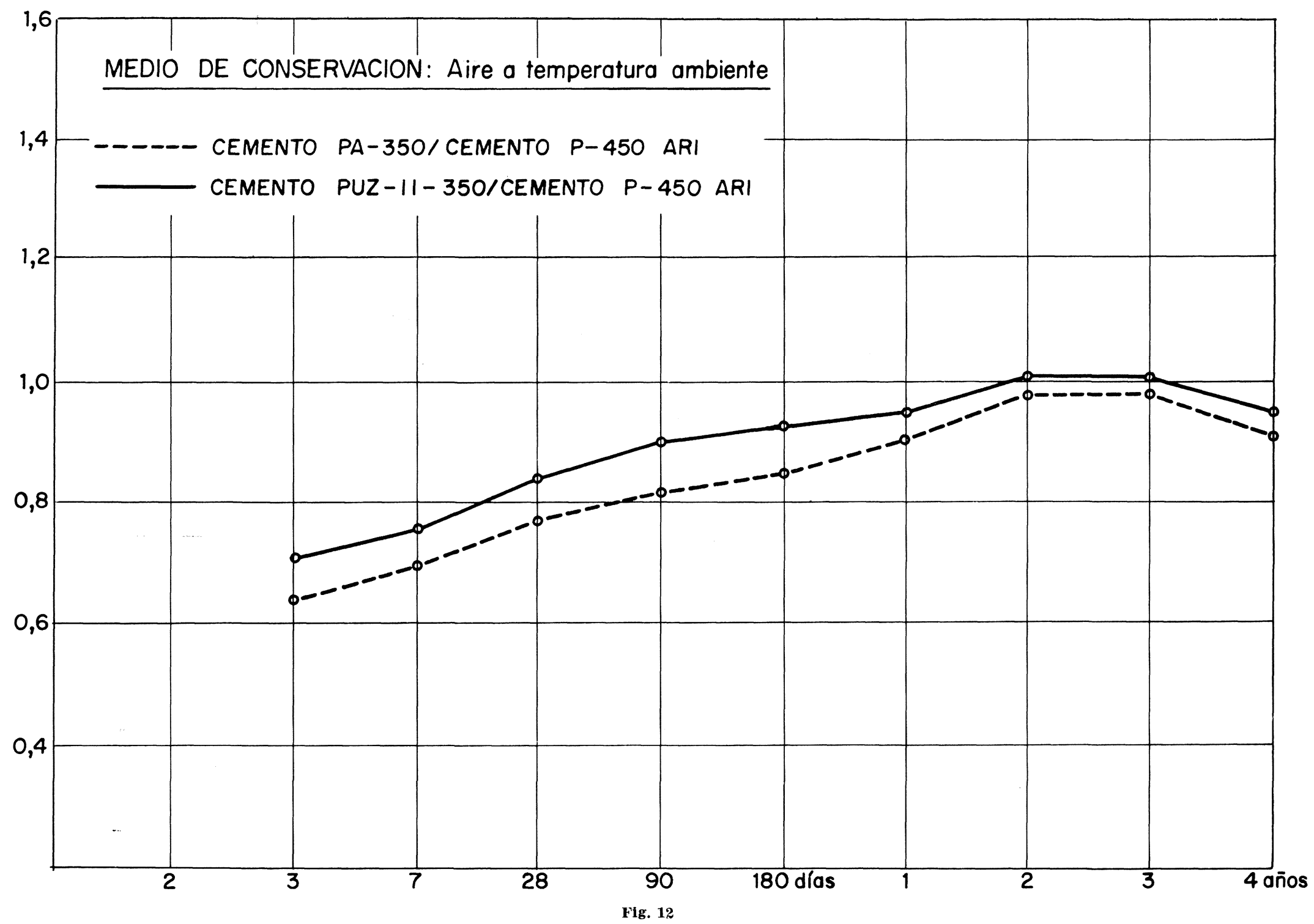




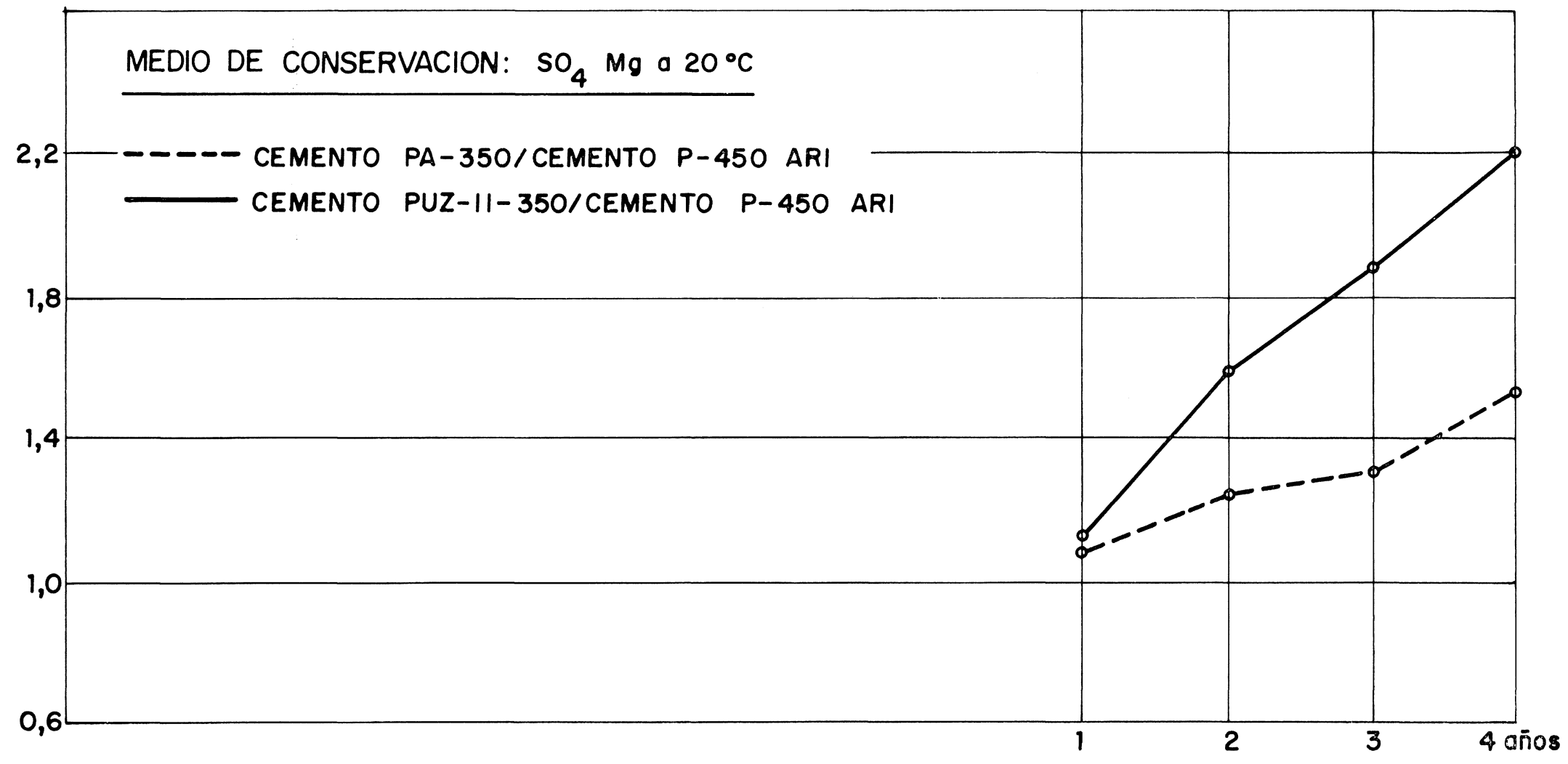

Fig. 13 


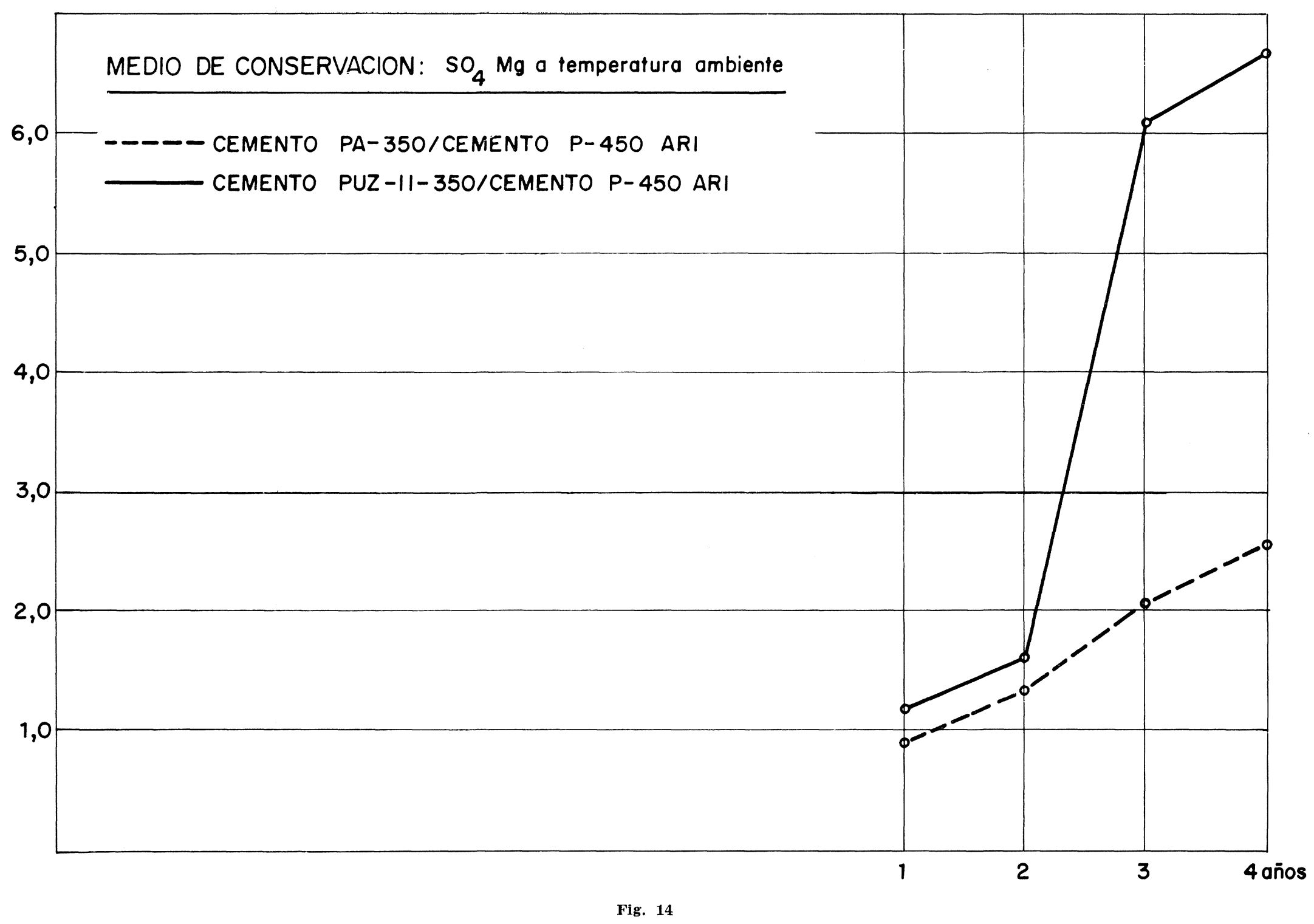


5.3.8.4. Medio de conservación: $\mathrm{SO}_{4} \mathrm{Mg}$ al $5 \%$ a $20^{\circ} \mathrm{C}$.

\begin{tabular}{lcc}
\hline EDAD & I & II \\
\hline 1 año & 1,08 & 1,13 \\
2 años & 1,24 & 1,60 \\
3 años & 1,31 & 1,87 \\
4 años & 1,53 & 2,19 \\
\hline
\end{tabular}

Estos valores se representan en la figura 13.

5.3.8.5. Medio de conservación: $\mathrm{SO}_{4} \mathrm{Mg}$ al $5 \%$ a temperatura ambiente.

\begin{tabular}{lcc}
\hline EDAD & I & II \\
\hline 1 año & 0,93 & 1,18 \\
2 años & 1,32 & 1,60 \\
3 años & 2,07 & 6,07 \\
4 años & 2,55 & 6,63 \\
\hline
\end{tabular}

Estos valores se representan en la figura 14.

\section{INTERPRETACION DE RESULTADOS}

De los resultados obtenidos en los ensayos y pruebas realizadas podemos concluir que es una buena solución el emplear cenizas volantes para fabricar cementos de los tipos PA o PUZ-II definidos según RC-75.

Los cementos estudiados que contienen aproximadamente $13 \%$ de cenizas volantes (cemento tipo PA) y $23 \%$ de cenizas volantes (cemento tipo PUZ-II), cumplen todas las condiciones físicas, químicas y mecánicas exigidas por el pliego vigente RC-75.

En cuanto a las posibles mejoras que se han podido constatar en dichas propiedades, al comparar los cementos con cenizas (PA y PUZ-II) con el cemento portland puro, podemos indicar:

- Las cenizas volantes presentes en los cementos tipo PA y PUZ-II reaccionan químicamente con la cal liberada en el proceso de hidratación del cemento.

A temperatura de $40^{\circ} \mathrm{C}$ (indicada por la norma) la reacción es ya importante en un plazo de 7 y 28 días - lo es más a medida que el contenido en cenizas aumenta-. Los ensayos han permitido determinar que la reacción tiene lugar también a la temperatura de $20^{\circ} \mathrm{C}$ e inferior (temperatura ambiente de nuestra zona) si bien requiere más tiempo.

- Las resistencias mecánicas de los morteros de los cementos PA y PUZ-II, frente a las soluciones agresivas de $\mathrm{SO}_{4} \mathrm{Mg}$ al $5 \%$, son mucho mayores que las del cemento portland puro P-450 ARI, el cual ya a la edad de 3 años, en la solución conservada a la temperatura ambiente se degrada de manera muy importante.

- Las probetas conservadas en agua a $20^{\circ} \mathrm{C}$ de los cementos PA y PUZ-II alcanzan los mismos valores de resistencia que el cemento portland puro P-450-ARI a las edades de 180 y 90 días respectivamente (tal como se observa en la gráfica 10). A edades más avanzadas las resistencias son aún mayores. 
- Cuando las probetas se conservan en agua a la temperatura ambiente, si bien tardan más tiempo en alcanzar la resistencia del P-450-ARI, lo hacen a una edad inferior a 1 año, y luego continúan siendo mayores.

- A igualdad de finura, la estabilidad de volumen se ve mejorada de manera muy importante en el cemento con mayor contenido de cenizas (PUZ-II-350, aproximadamente $23 \%$ ).

- Las cifras del valor puzolánico determinado según el método de LEA (2) (diferencia del endurecimiento en función al aumento de la temperatura entre 20 y $50^{\circ} \mathrm{C}$ ) da valores muy altos para los cementos PA y PUZ-II (+ $\left.104 \mathrm{y}+165 \mathrm{~kg} / \mathrm{cm}^{2}\right)$, lo que indica la buena calidad de las cenizas volantes que se obtienen en las Centrales Térmicas no distantes de nuestras Factorías.

\section{AGRADECIMIENTO}

El autor quiere hacer constar su sincero agradecimiento, por la dirección, orientación y ayuda recibidas en una $u$ otra forma y medida, al Prof. Gonzalo VAZQUEZ UÑA, Catedrático de Química Técnica de la Universidad de Santiago de Compostela y Jefe del correspondiente Departamento en la Facultad de Química de dicha Universidad, a los Profesores Drs. Alberto ARCE y Antonio BLANCO, a don Arturo MARTINEZ MARTINEZ, Director Técnico de CEMENTOS NOROESTE, S. A. y a todos sus compañeros y colaboradores de los Laboratorios de la Fábrica de Cementos de Oural (Lugo), de la mencionada empresa.

\section{BIBLIOGRAFIA}

(1) Venuat, M.: "Revue des Materiaux de Construction" núms. 506, 565, 566 y 567. Edita: C.E.R.I.L.H París 1962.

(2) LEA, M. F.: “Química del cemento y del hormigón”. Ed. Edward Arnold. Londres 1960.

(3) Alonso Ramirez, J. L.: "Estudio físico-químico y técnico de diversos tipos de cenizas, y su empleo como materiales de construcción".

Publicación n. 199 del Laboratorio Central de Ensayos de Materiales de Construcción, 1969.

14) Papadakis, M., y Venuat, M.: "Fabricación, características y aplicaciones de diversos tipos de cementos".

Ed. Técnicos Asociados. Barcelona 1968.

(5) FLIEGO DE CONDICIONES PARA LA RECEPCION DE CONGLOMERANTES HIDRAULICOS. InStituto Eduardo Torroja de la Construcción y del Cemento, PCCH-64. 1964.

(6) RECEPCION DE CONGLOMERANTES. PLIEGO DE PRESCRIPCIONES TECNICAS GENERALES PARA LA RECEPCION DE CEMENTOS RC-75.

Boletín Oficial del Estado. Madrid 1975.

(7) ASINEL: "Las cenizas volantes y sus aplicaciones". Asociación de investigación eléctrica. Madrid 1970.

(8) JARRIGUE, A.: "Las cenizas volantes. Propiedades y aplicaciones industriales". Ed. Eyrolles. Paris 1971.

(9) KEIL, D. F.: “Cemento. Fabricación, Propiedades y Aplicaciones”. Ed. Técnicos Asociados. Barcelona 1973.

(10) Heft 33: "Mahl feinheit von Zement. Richt Linien Fur Die Bestimmung”. Verein Deutscher Zement Werke e.V., Dusseldorf. 